\title{
Matrix Assisted Ionization: New Aromatic and Nonaromatic Matrix Compounds Producing Multiply Charged Lipid, Peptide, and Protein lons in the Positive and Negative Mode Observed Directly from Surfaces
}

Jing Li, Ellen D. Inutan, Beixi Wang, Christopher B. Lietz, Daniel R. Green, Cory D. Manly, Alicia L. Richards, Darrell D. Marshall, Steven Lingenfelter, Yue Ren, Sarah Trimpin

Department of Chemistry, Wayne State University, Detroit, MI 48202, USA

\begin{abstract}
Matrix assisted inlet ionization (MAll) is a method in which a matrix:analyte mixture produces mass spectra nearly identical to electrospray ionization without the application of a voltage or the use of a laser as is required in laserspray ionization (LSI), a subset of MAll. In MAll, the sample is introduced by, for example, tapping particles of dried matrix:analyte into the inlet of the mass spectrometer and, therefore, permits the study of conditions pertinent to the formation of multiply charged ions without the need of absorption at a laser wavelength. Crucial for the production of highly charged ions are desolvation conditions to remove matrix molecules from charged matrix: analyte clusters. Important factors affecting desolvation include heat, vacuum, collisions with gases and surfaces, and even radio frequency fields. Other parameters affecting multiply charged ion production is sample preparation, including $\mathrm{pH}$ and solvent composition. Here, findings from over 100 compounds found to produce multiply charged analyte ions using MAll with the inlet tube set at $450{ }^{\circ} \mathrm{C}$ are presented. Of the compounds tested, many have $-\mathrm{OH}$ or $-\mathrm{NH}_{2}$ functionality, but several have neither (e.g., anthracene), nor aromaticity or conjugation. Binary matrices are shown to be applicable for LSI and solvent-free sample preparation can be applied to solubility restricted compounds, and matrix compounds too volatile to allow drying from common solvents. Our findings suggest that the physical properties of the matrix such as its morphology after evaporation of the solvent, its propensity to evaporate/sublime, and its acidity are more important than its structure and functional groups.
\end{abstract}

Key words: Matrix assisted inlet ionization (MAII), Laserspray ionization inlet LSII), Solvent assisted inlet ionization (SAII), Laserspray ionization vacuum (LSIV), Multiply charged ions, Linear and nonaromatic matrices, Solvent-free, Dissolved MAIl, Electron transfer dissociation (ETD)

Electronic supplementary material The online version of this article (doi:10.1007/s13361-012-0413-z) contains supplementary material, which is available to authorized users.

Correspondence to: Sarah Trimpin; e-mail: STrimpin@chem.wayne.edu

\section{Introduction}

$\mathrm{M}$ atrix-assisted laser desorption/ionization (MALDI) mass spectrometry (MS) [1, 2], along with electrospray ionization (ESI) [3], has had an enormous impact on 
science. In spite of the importance and world-wide use, the ionization mechanisms of MALDI [4-8] and, to a lesser degree, ESI [9-13] are still in dispute. For MALDI, the two most prominent models are the cluster model $[14,15]$ and the photochemical ionization model $[16,17]$. Mechanisms in MALDI have been predicated on production of singly charged ions, although Karas et al. [14] proposed a model involving multiply charged matrix:analyte clusters in which charge reduction of multiply charged ions produced from laser-induced clusters led to the observed singly charged 'lucky survivors'. This model was subsequently modified in favor of direct production of singly charged ions from laser produced clusters [15]. More recently, this model was modified to a unified mechanism [18]. For ESI, the two prominent mechanisms are ion evaporation and charge residue $[19,20]$.

Laserspray ionization inlet (LSII) [21-25] provides an alternative approach to atmospheric pressure (AP) MALDI [26] in which production of high charge state ions, similar to ESI, using laser ablation of a matrix:analyte mixture reduces instrument-related mass range limitations and enhances structurally significantly mass selected fragmentation [23, 27]. This newly introduced inlet ionization method also offers the possibility of significantly better sensitivity than AP-MALDI because ionization occurs inside the heated inlet capillary between AP and vacuum $[23,28]$ eliminating socalled rim ion loss issues [29]. Besides producing ESI-like multiply charged ions, LSII was shown to involve a different ionization mechanism from MALDI [23, 28, 30]. Essentially identical results were obtained from the same bovine serum albumin (BSA) $\sim 66 \mathrm{kDa}$ sample producing up to 67 charges by introducing the matrix:analyte mixture field free into a heated inlet tube linking AP with the first vacuum region of the mass analyzer using laser ablation (LSII) or by tapping (matrix assisted inlet ionization or MAII) [31]. Thus, in LSII the laser is a high spatial resolution means of transferring the matrix:analyte to the inlet of the mass spectrometer which is important for imaging applications [27, 32-34]. Inlet ionization has recently been extended to solvents as matrices, so called solvent assisted inlet ionization (SAII), and hyphenated to liquid chromatography [35-37].

A great deal of study has gone into developing and understanding matrix compounds in MALDI including pure solids [38-57], binary solids [58-61], and liquids [62-64], but at the start of this study 2,5-dihydroxybenzoic acid (2,5DHB) [22, 23], 2,5-dihydroxyacetophenone (2,5-DHAP) [24, 30], 2-aminobenzyl alcohol (ABA), anthranilic acid (2-aminobenzoic acid), and 2-hydroxyacetophone (HAP) [65], were the only known MAII and LSII matrices. In LSII, matrix:analyte droplets caused by laser ablation were reported $[28,66]$. 2,5-DHAP was found to require significantly lower inlet temperature than 2,5-DHB, which was attributed to lower temperature requirement for evaporation/ sublimation necessary for desolvation of charged droplets (clusters) and releasing of bare analyte ions [30, 33, 66, 67]. Extending the concept of the importance of desolvation of charged droplets in producing multiply charged ions led to the production of multiply charged ions, similar to ESI and LSII, using the matrix 2,5-DHAP with an intermediate pressure (IP) MALDI ion source; 2,5-DHB produces only low abundance multiply charged ions at IP [68]. We hypothesized that desolvation could be achieved even under vacuum conditions using more volatile matrix compounds, or alternatively, by increasing the thermal energy supplied for desolvation. By expanding the use of laserspray ionization at IP and low pressure (LP) conditions (e.g., MALDITOF instruments), better sensitivity might be achieved relative to AP ionization [69]. Initially, it was expected that the type and positions of functionalities in matrix compounds are important in MAII and LSI, as expected in MALDI [38-64]. In analogy to MALDI [53, 70-93], sample preparation was assumed to also be important.

Our original goal was to understand the structural elements of a matrix that are necessary for formation of multiply charged ions in LSI and MAII at AP, IP, and LP and discover more volatile matrices, which could be used under vacuum conditions. Based on assumptions of necessary structural elements for 'good' matrices, we looked at ion abundances and charge states produced for peptides, small proteins, and lipids using a variety of potential matrix compounds, with and without the anticipated 'good' structural elements. Here, we report on $>100$ small molecules having a wide range of structures that were tested as matrix compounds for MAII or LSII at high and low inlet temperature and for use in vacuum ionization in the absence of an inlet. Although, based on our hypothesis, it was expected that higher temperature would improve ionization through matrix desolvation, we were nevertheless astonished that at $450{ }^{\circ} \mathrm{C}$, a large majority of the compounds tested produced multiply charged ions by MAII and, subsequently, many of these by LSII. Many of the compounds with anticipated 'poor' structural elements functioned as MAII or LSI matrices. Of the well performing matrices, three matrices, and binary matrix compositions thereof, produced multiply charged ions of peptides, proteins, and synthetic polymers at IP on a commercial IP-MALDI source without the need for an heated inlet. One of these compounds produced stable multiply charged ions on a commercial MALDI-TOF mass spectrometer at LP conditions [94]. Further, initial results related to analytical utility [31] and the mechanistic insights obtained from this study are addressed separately [95].

\section{Experimental}

\section{Materials}

Matrices were purchased from Sigma Aldrich (St. Louis, MO, USA), Fisher Scientific (Pittsburgh, PA, USA), Matrix Scientific (Columbia, SC, USA), Supelco (Bellefonte, PA, USA), and Alfa Aesar (Ward Hill, MA, USA). Acetonitrile $(\mathrm{ACN})$, methanol $(\mathrm{MeOH})$, trifluoroacetic acid (TFA), acetic acid (AA), formic acid (FA), and hydrochloric acid ( $\mathrm{HCl})$ were purchased from Fisher Scientific (Pittsburgh, PA, 
USA), and angiotensin I (from human) from American Peptide (Sunnyvale, CA, USA). Insulin (from bovine pancreas), ubiquitin (from bovine erythrocytes), lysozyme (from chicken eggwhite), myoglobin, carbonic anhydrase, and ganglioside GD1 ${ }_{\mathrm{a}}$ were obtained from Sigma Aldrich. Purified water was obtained from EMD Chemicals (Gibbstown, NJ, USA). Microscopy glass slides $(76.2 \mathrm{~mm} \times 25.4 \mathrm{~mm} \times$ $1 \mathrm{~mm}$ ) were purchased from Gold Seal Products (Portsmouth, NH, USA).

\section{Sample Preparation}

For MAII and LSII studies, stock solutions of angiotensin I, ubiquitin, lysozyme, myoglobin, and carbonic anhydrase were prepared in pure water, ganglioside $\mathrm{GD}_{\mathrm{a}}$ in pure methanol, and bovine insulin in 50:50 MeOH: $\mathrm{H}_{2} \mathrm{O}$ with $1 \%$ AA to allow the sample to be completely dissolved. Matrix solutions were prepared individually by dissolving $5 \mathrm{mg}$ of each matrix in $100 \mu \mathrm{L}$ 50:50 ACN: $\mathrm{H}_{2} \mathrm{O}$ except for the following: $\alpha$-cyano-4-hydroxycinnamic acid (CHCA, $(E)-2-$ cyano-3-(4-hydroxyphenyl)prop-2-enoate) in $500 \mu \mathrm{L}, 2,5-$ DHB in $50 \mu \mathrm{L}, 4,4^{\prime}$-azobis(4-cyanovaleric acid) in $60 \mu \mathrm{L}$, and 2,5-DHAP in $150 \mu \mathrm{L}$ (warmed), anthracene-9-carboxylic acid (Fisher Scientific) in $1 \mathrm{~mL}$ and 3,4-DHAP in $100 \mu \mathrm{L}$ (water). For the high mass $\mathrm{pH}$ study, angiotensin I, ubiquitin, lysozyme, myoglobin, carbonic anhydrase and bovine insulin were diluted to 5 pmol $\mu \mathrm{L}^{-1}$ with pure water. 2-Amino-3nitrophenol matrix solution was pre-acidified by dissolving $10 \mathrm{mg}$ in $300 \mu \mathrm{L}$ 50:50 ACN: $\mathrm{H}_{2} \mathrm{O}$ with $1 \%$ AA. Other acidified matrix solutions were prepared as follows: $2,2^{\prime}$-azobis (2-methylpropionitrile) with $1 \% \mathrm{AA}$, dimethyl fumarate ([E]2-butenedioic acid dimethyl ester), 2,4,6-trimethoxybenzoic acid, and 3,4,5-trimethoxybenzoic acid with $0.1 \%$ FA. For the anthracene $\mathrm{pH}$ study, $5 \mathrm{pmol} \mu \mathrm{L}^{-1}$ ubiquitin in water was acidified with $0.1 \% \mathrm{FA}, 0.1 \% \mathrm{TFA}, 1 \% \mathrm{AA}$, and $1 \% \mathrm{HCl}$, and anthracene solution in 50:50 ACN:water acidified with $1 \%$ $\mathrm{HCl}$. For matrices that were acidified to lower the $\mathrm{pH}, 0.1 \%$ to $3 \% \mathrm{FA}$ was added into the matrix solution. For the solvent study, 2,5-DHAP was dissolved in 100\% ACN, 50:50 ACN: water, and acidified with $0.1 \% \mathrm{FA}, 1 \% \mathrm{AA}, 2 \% \mathrm{AA}$, and $1 \%$ $\mathrm{HCl}$. For dissolved MAII and SAII studies, the stock solution of ubiquitin was diluted to $2.5 \mathrm{pmol} \mu \mathrm{L}^{-1}$ with $50: 50 \mathrm{ACN}$ : $\mathrm{H}_{2} \mathrm{O}$, and then $0.2 \mu \mathrm{L}$ matrix solution was added into $200 \mu \mathrm{L}$ of $2.5 \mathrm{pmol} \mu \mathrm{L}^{-1}$ ubiquitin solution.

\section{Solvent-Based Sample Preparation}

The layer method was used as previously described [25]. In brief, $1 \mu \mathrm{L}$ of $5 \mathrm{pmol} \mu \mathrm{L}^{-1}$ analyte solution was spotted on a glass slide and $2 \mu \mathrm{L}$ of matrix solution was added on top (1 $\mu \mathrm{L}$ mixed and the other $1 \mu \mathrm{L}$ without mixing), and air-dried. For azobis matrix, $1 \mu \mathrm{L}$ of $5 \mathrm{pmol} \mu \mathrm{L}^{-1}$ analyte solution was added on top of $2 \mu \mathrm{L}$ of matrix solution spotted on a glass slide and air-dried. For binary matrices, $10 \mathrm{mg} \mathrm{mL}^{-1} \mathrm{CHCA}$ and $25 \mathrm{mg} \mathrm{mL}^{-1}$ sinapinic acid (SA, 3-(4-hydroxy-3,5dimethoxyphenyl)prop-2-enoic acid) in 50:50 ACN: $\mathrm{H}_{2} \mathrm{O}$ were mixed with 2-nitrophloroglucinol (2-NPG, 2-nitrobenzene-1,3,5-triol) $(5 \mathrm{mg}$ in $100 \mu \mathrm{L})$ solution by $5: 95(2-$ NPG:CHCA, 2-NPG:SA) volume ratio for AP, 10:90 and 50:50 (2-NPG:SA) volume ratio for IP and LP measurements, respectively. Sensitivity comparison studies were obtained by spotting $1 \mu \mathrm{L}$ of 10 and $50 \mathrm{fmol} \mu \mathrm{L}^{-1}$ bovine insulin solution acidified with $1 \% \mathrm{AA}$ on a glass slide separately and followed by $1 \mu \mathrm{L}$ of 2-NPG and $1 \mu \mathrm{L}$ of $2,5-$ DHAP matrix solution, respectively. The dried-droplet method was used for the binary matrix study using LSI vacuum (LSIV) where $5 \mathrm{pmol} \mu \mathrm{L}^{-1}$ analyte solution was premixed with the matrix solution in 1:1 volume ratio and 1 $\mu \mathrm{L}$ of the matrix:analyte mixture was spotted on a glass slide and air dried [68, 94].

\section{Solvent-Free Sample Preparation}

Ten microliters of $1 \mathrm{mg} \mathrm{mL}^{-1}\left(772 \mathrm{pmol} \mu \mathrm{L}^{-1}\right)$ solution of angiotensin I in water, $10 \mu \mathrm{L}$ of $1 \mathrm{mg} \mathrm{mL}^{-1}\left(545 \mathrm{pmol} \mu \mathrm{L}^{-1}\right)$ GD1 ${ }_{\mathrm{a}}$ in methanol, and $10 \mu \mathrm{L}$ of 100 pmol $\mu \mathrm{L}^{-1}$ ubiquitin in water were dried in separate $200 \mu \mathrm{L}$ PCR tubes in the Biodryer (BioSpec Products, Bartlesville, OK, USA), and homogenized with a TissueLyser II (Qiagen, Valencia, CA, USA), after addition of a spatula tip amount of matrices powder, similar to the published procedure [66]. The homogenization was set at $25 \mathrm{~Hz}$ frequency for $10 \mathrm{~min}$ grinding time where the ground matrix:analyte sample was simultaneously transferred to a glass slide.

\section{Evaporation Experiment}

2-NPG, 2,5-DHAP, 2,5-DHB, CHCA, and SA matrices were used in this experiment. One $\mu \mathrm{L}$ of each matrix solution was spotted on a MALDI plate and air dried. The plate was loaded into the SYNAPT G2 MALDI source operating at IP and a picture capture of each spot was taken initially and then at 30-min intervals for $4 \mathrm{~h}$ and again after $14 \mathrm{~h}$ total. At AP, the MALDI plate with a $1 \mu \mathrm{L}$ spot of each of the matrix solutions was placed on top of a hot plate. Observations were made over a 5 -min period.

\section{Laser Impact Angle Experiment}

2,5-DHAP, 2-NPG, and methyl succinic acid matrices were used to perform transmission geometry (TG) and reflection geometry (RG) experiments. Matrix:analyte mixture was prepared by 1:1 layer method on a glass slide and ablated using a nitrogen laser $(337 \mathrm{~nm})$. An optical microscope (Nikon Eclipse LV100) was used to capture photographs of the ablated area at $5 \times$ magnification similar to previous studies $[28,66]$.

\section{Inlet Ionization Mass Spectrometry}

An LTQ-Velos mass spectrometer (Thermo Fisher Scientific, Bremen, Germany) with a commercially available heated inlet 
ion transfer tube was used for MAII, LSII, SAII, and dissolved MAII studies according to the published procedures [27, 31-37, 96]. In brief, the API source housing was removed. For MAII, the sample was transferred to the inlet by tapping the dried matrix:analyte mixture applied to a glass slide against the mass spectrometer inlet [31, 96], and in LSII, the focused nitrogen laser (Spectra Physics VSL-337ND-S; Mountain View, CA, USA) ablated the solid matrix:analyte sample into the inlet [27, 31-33]. In SAII, the analyte dissolved in a solvent, and in dissolved MAII the analyte dissolved in a solvent along with dissolved matrix [34], are introduced into the mass spectrometer inlet in the liquid state using $150 \mu \mathrm{m}$ i.d. fused silica tubing (Polymicro Technologies, Phoenix, AZ, USA) directly [35-37], or simply pipetting the solution into the mass spectrometer inlet [37]. The temperature applied on the mass spectrometer inlet tube was $450{ }^{\circ} \mathrm{C}$ unless specified differently. Matrices that performed well at high inlet temperatures were examined as low as $50^{\circ} \mathrm{C}$. MAII and LSII mass spectra are obtained by setting the maximum injection time to $50 \mathrm{~ms}$ and microscans to two. Electron transfer dissociation (ETD) fragmentation was obtained on the LTQ-ETD Velos for charge state +11 of ubiquitin using dissolved MAII similar to LSII-ETD previously described [23, 27]. A Waters SYNAPT G2 mass spectrometer with IMS capability was also used for LSII employing the nanoESI source as described in detail in [24, 25]. Different designs of the homebuilt skimmer cone were used including straight copper and glass tubes and a $90^{\circ}$ bent stainless steel tube. The source temperature was set at $150{ }^{\circ} \mathrm{C}$. Acquisition conditions were resolution mode with $40 \mathrm{~V}$ sample cone and $4 \mathrm{~V}$ extraction cone settings. The scan time of 1 scan per $\mathrm{s}$ and with up to $1 \mathrm{~min}$ acquisition times were used. MassLynx 4.1 software was used to extract the mass spectrum.

\section{LSI Vacuum (LSIV) Mass Spectrometry}

Matrices that worked well at low inlet temperature in MAII and LSII were tested for the utility to provide multiply charged ions under vacuum conditions without the benefit of a heated inlet. A variety of different binary matrix compositions were also examined using the best MAII matrix, 2-NPG, dissolved with MALDI matrices, (e.g., CHCA and SA) and air dried. A SYNAPT G2 mass spectrometer with an IP-MALDI source equipped with a Nd:YAG laser $(355 \mathrm{~nm}, 200 \mathrm{~Hz})$ was used, as noted in previous work $[68,94]$. The instrument was operated in positive ion and sensitivity modes with $0 \mathrm{~V}$ on the sample plate, a $10 \mathrm{~V}$ "extraction," $10 \mathrm{~V}$ "hexapole bias," and $5 \mathrm{~V}$ "aperture 0" settings. The dried droplet method was used to spot $1 \mu \mathrm{L}$ of the analyte:matrix mixture onto the glass plate. After the sample plate was loaded into the MALDI source, the sample pressure was at 0.216 mbar and the drift cell pressure at 3.25 mbar. The laser fluence used was set to 170 and 225 (arbitrary units) respectively, at a $200 \mathrm{~Hz}$ firing rate. The total acquisition time was 1 to 2 min with 1 scan per s. Autoflex Speed mass spectrometer (Bruker, Bremen, Germany) was employed for the LP-LSI study of pure and binary matrices employing reported instrument conditions [94]. The mass spectrometer was operated in reflectron positive ion mode. The ion source voltage (ISV) 1, ISV 2, lens voltage, rf and rf2 were set $19,16.8,8,21$, and $9.65 \mathrm{kV}$, respectively.

\section{Results}

Ion abundances in the inlet ionization methods LSII, MAII, and SAII (Scheme 1, Scheme S1) have been shown to be a function of the AP to vacuum inlet temperature [23, 28, 66]. This temperature effect has been associated with matrix or solvent droplet charging and desolvation (Scheme 1). An approach for enhancing matrix dependent inlet ionization (Scheme 1a) is through discovery of matrix compounds that efficiently produce charged droplets/particles and desolvate under the available experimental conditions. Finding compounds having these features under vacuum conditions (Scheme 1b) was of interest because of the possibility of further enhancing sensitivity by eliminating losses associated with ion transfer from AP to vacuum. In order to determine structural elements useful for good matrix compounds without the necessity of absorption at a particular laser wavelength, we screened 176 compounds using MAII with an inlet temperature of $450{ }^{\circ} \mathrm{C}$ using the commercially heated inlet tube capabilities of the LTQ Velos. Of the small molecules screened, surprisingly, 137 provided abundant multiply charged ions (Scheme 2, Figure 1 and S1: common MALDI matrices and respective isomers, Scheme 3, Figure 2, and S2A: aromatic compounds, and Scheme 4, Figure 3 and S2B: nonaromatic and linear compounds). Matrices that provided the highest ion abundance at an inlet temperature of $450{ }^{\circ} \mathrm{C}$ are summarized for positive (Table S1) and negative ion mode measurements (Table S2). These matrices were subsequently analyzed at temperatures as low as $50^{\circ} \mathrm{C}$ (Figure S3). Compounds that do not provide significant ions at $450{ }^{\circ} \mathrm{C}$ or increase the charge state in dissolved MAII relative to SAII are listed in Table S3.

Several matrices using solvent-free sample preparation conditions were also tested (Figure 4 and S4). The influence of the solvent composition (Figure S5), $\mathrm{pH}$ (Figure S6), counter anions (Figure S7), the applicability for negative mode (Figure 5 and S8), and high-mass measurements (Figure S9) were further considered for a selected set of matrix compounds. The applicability for LSI (Figure 2II.b, Figure S10) was determined for aromatic and nonaromatic compounds, and the influence of the laser alignment in TG versus RG studied (Figure S11) similar to previous reports using AP- and vacuum MALDI $[30,97,98]$. Matrices and sample preparation conditions that produced exceptional results at low inlet temperatures were further investigated on instruments lacking a heated inlet tube such as the SYNAPT G2 nano-ESI skimmer cone ion entrance, the SYNAPT G2 IP-MALDI source, and the Bruker LP-MALDI-TOF vacuum source. Binary matrices were tested at AP, IP, and LP (Figure S12). Collisions of multiply charged droplets/ particles with surfaces, as well as radio frequency (rf) fields presumably aid desolvation (Figure S13). Lipids, peptides, and proteins were analyzed. 


\section{(a) Inlet lonization: LSII, MAll, SAll}

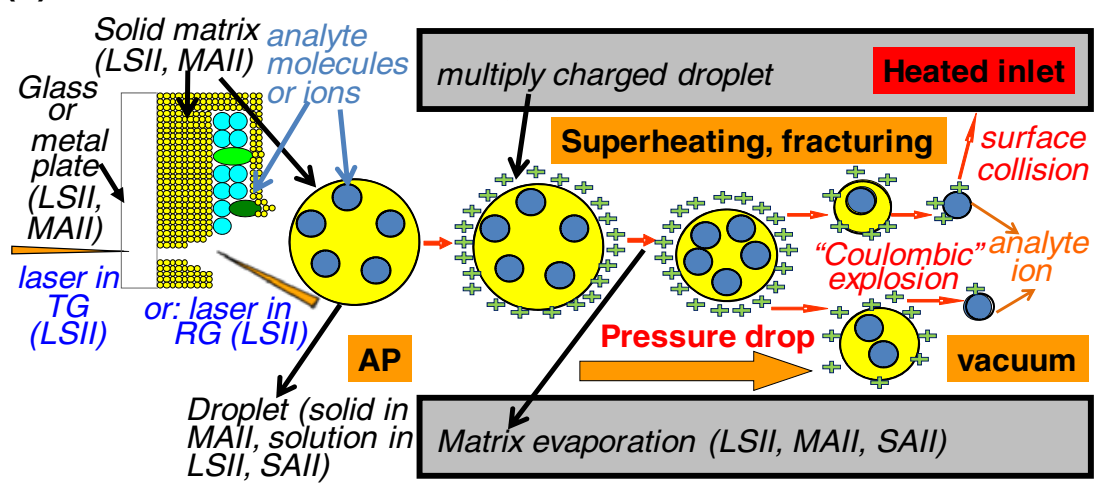

(b) Vacuum lonization: LSIV

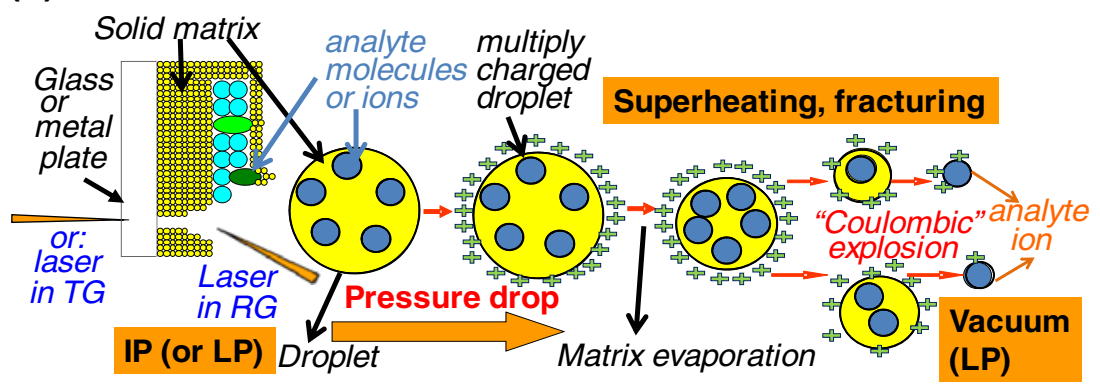

Scheme 1. Schematic representation of ion formation in (a) inlet and (b) vacuum ionization

\section{Matrices Tested using Matrix Assisted Inlet Ionization}

Structural commonalities of the successful MAII matrices may reflect our selection of compounds to test based on preconceived expectations from structural elements of previously successful MALDI (Scheme 2) and LSII matrix compounds. With this caveat, the better matrix compounds were found to have two or more functional groups, one of which is a $-\mathrm{OH}$ or $-\mathrm{NH}_{2}$ group (Schemes 3 and 4). One of the other functional groups of the better matrices is also an electron withdrawing group consisting of $-\mathrm{CO}_{2} \mathrm{H}$, $-\mathrm{COCH}_{3},-\mathrm{NO}_{2}$, or $-\mathrm{CF}_{3}$, with compounds having an $\mathrm{NO}_{2}$ or other good leaving groups ('explosophores' [99]) sometimes providing exceptional performance. However, some well performing matrices were discovered that have none of these structural elements, especially with sufficient heat provided. The results relative to functional groups are summarized according to carboxylic acids (Table S1A), acetophenones (Table S1B), benzaldehydes (Table S1C), benzamides (Table S1D), phenols/alcohols (Table S1E), nitro (Table S1F), cyano (Table S1G), and halogenated compounds (Table $\mathrm{S} 1 \mathrm{H}$ ), sulfonic acids and sulfonates (Table S1I), amines (Table S1J), hydrazides (Table S1K), pyridines (Table S1L), naphthalenes (Table $\mathrm{S} 1 \mathrm{M})$, anthracenes (Table $\mathrm{S} 1 \mathrm{~N})$, as well as cyclic nonaromatic (Table S1O), linear conjugated (Table S1P), linear nonconjugated (Table S1Q), and thermally labile compounds (Table S1R).
Investigations of known DHB [38, 47, 53] and DHAP $[40,41,100]$ MALDI matrices, and their respective isomers all produced highly charged ions (Figure S1.A, B), with different abundances at $450{ }^{\circ} \mathrm{C}$. Caffeic acid $(3-[3,4-$ dihydroxyphenyl]-2-propenoic acid) [101] produces charge states for ubiquitin (MW 8560) up to +12 (Figure 1a: ubiquitin). Other known MALDI matrices [38, 42, 46, 49, 102-106] such as 6-aza-2-thiothymine (Figure 1b: myoglobin), anthranilic acid (2-aminobenzoic acid), 5-methylsalicylic acid, 2,4,6-trihydroxyacetophenone, 5-bromo-2hydroxybenzohydrazide, 4-nitroaniline, 3-hydroxypicolinic acid, and nicotinic acid (pyridine-3-carboxylic acid) produce multiply charged MAII ions, though the abundances vary greatly (Figure S1C). The least abundant multiply charged ion formation is observed with CHCA ([E]-2-cyano-3-[4hydroxyphenyl]prop-2-enoate) and SA (3-[4-hydroxy-3,5dimethoxyphenyl]prop-2-enoic acid) matrices (Figure S12). In a temperature study from 450 to $50{ }^{\circ} \mathrm{C}$ using salicylamide (2-hydroxybenzamide) and 3,4-DHAP, the ion abundance strongly decreases with decreasing inlet temperature (Figure S3) as previously observed [23].

MAII results of hitherto unknown aromatic matrices for use in MS are shown for 1,4-dihydroxy-4,6-dimethoxybenzene (DHDMB) (Figure 2I: non-acidified) and 2-amino-3nitrophenol (Figure 2II.a: acidified) for the analyses of lysozyme (MW 14,300) producing up to +14 charge state with +12 as the most abundant. Other well performing matrices include 2,4-dihydroxybenzaldehyde and 2-naphthol (2-hydroxynaphthalene) both producing up to +11 charge 
(a) DHB isomers: $\mathbf{R}^{1}=-C_{\mathrm{OH}}^{\text {II }}$<smiles>[R]c1cc(O)ccc1O</smiles>

2,5-isomer $R^{1}:$ m.p. $204-208^{\circ} \mathrm{C}$ $R^{2}$ : m.p. $204-206^{\circ} \mathrm{C}$

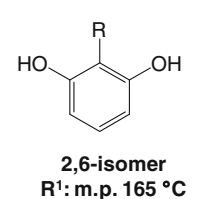

$R^{2}:$ m.p. $156-158^{\circ} \mathrm{C}$ (b) DHAP isomers: $R^{2}=-C_{H}^{\prime \prime}$

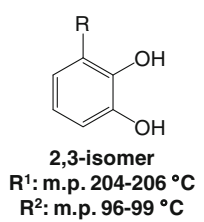

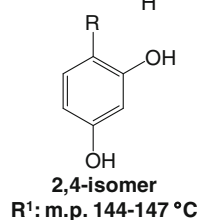

$R^{1}$ : m.p. $144-147^{\circ} \mathrm{C}$

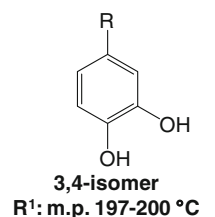

$R^{1}:$ m.p. $197-200^{\circ} \mathrm{C}$
$R^{2}:$ m.p. $117-119^{\circ} \mathrm{C}$

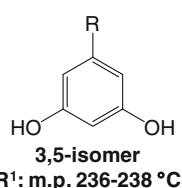

$R^{1}:$ m.p. $236-238^{\circ} \mathrm{C}$

$R^{2}:$ m.p. $145-146^{\circ} \mathrm{C}$

(c) Other MALDI matrices:

\section{c.1) Carboxylic acids}

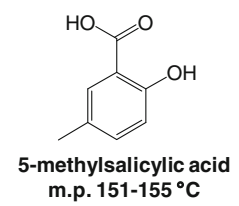

m.p. $151-155^{\circ} \mathrm{C}$

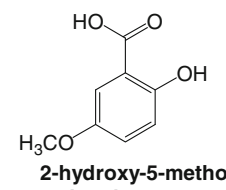

benzoic acid m.p. 141-143 ${ }^{\circ}$

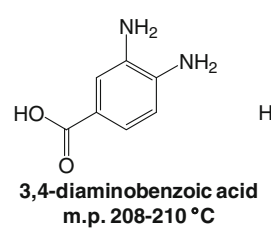

c.2) Acetophenone

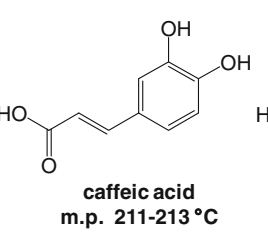

c.3) Benzamide

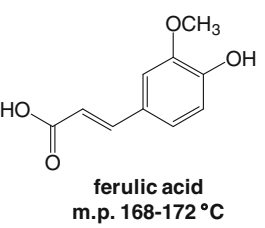

c.4)

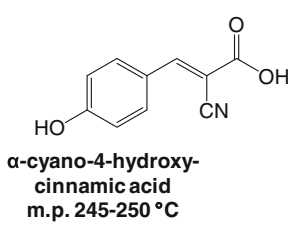

c.6) Amine

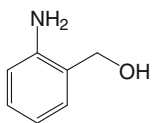

2-aminobenzyl alcohol m.p. $81-83^{\circ} \mathrm{C}$

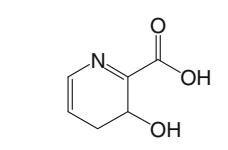

3-hydroxypicolinic acid m.p. $208-212{ }^{\circ} \mathrm{C}$

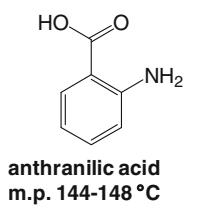

c.7) Pyridines

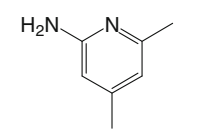

2-amino-4,6-dimethylpyridine m.p. $63-64^{\circ} \mathrm{C}$

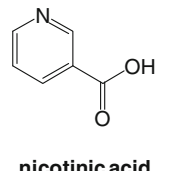

m.p. 236-239 ${ }^{\circ} \mathrm{C}$
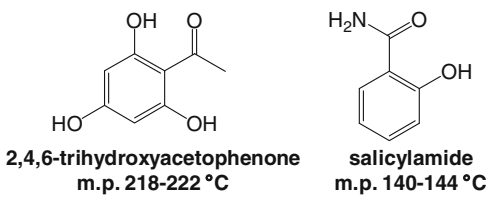

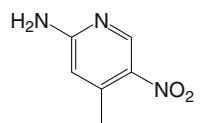

2-amino-5-nitro-4-picoline m.p. $223-225^{\circ} \mathrm{C}$

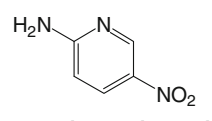

2-amino-5-nitropyridine m.p. $185-190^{\circ} \mathrm{C}$

c.8) Other basic matrices:

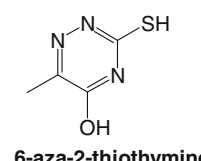

6-aza-2-thiothymin

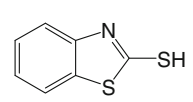

2-mercaptobenzothiazole m.p. $179^{\circ} \mathrm{C}$
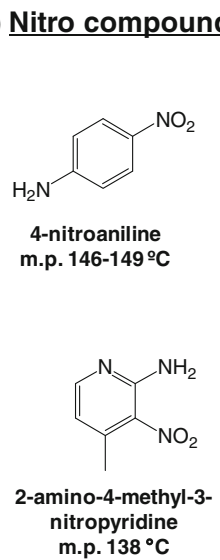

c.9) Anthracene

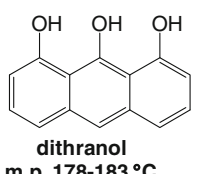

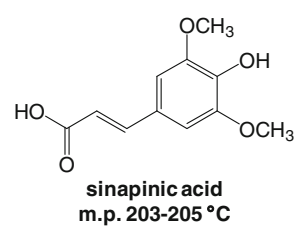

m.p. $203-205^{\circ} \mathrm{C}$

Scheme 2. Common MALDI matrices and isomers used as MAll matrices

state of ubiquitin (Figure S2A). As observed previously [31, 94-96], the chemical background of well performing MAII matrices is minute. A temperature study shows that abundant multiply charged ions are observed for acidified bovine insulin with DHDMB (Figure S3) as low as $50{ }^{\circ} \mathrm{C}$. Resorcinol (1,3-dihydroxybenzene), one of a few MAII aromatic structures tested that diverges from 1,2-substitution did not produce multiply charged ions for ubiquitin dissolved in water, but with ubiquitin dissolved in $0.1 \% \mathrm{FA}$ and for insulin dissolved in 50:50 MeOH:water with 1\% AA (Figure S2, S7), abundant multiply charged ions are observed. Other aromatic matrices diverging from the 1,2-substitution, which also produce multiply charged ions of bovine insulin when acidified, include 1,3-dicyanobenzene, 1,4-dicyanobenzene, hydroquinone (1,4-dihydroxybenzene), 4-nitroaniline (p-aminonitrobenzene) and 3,5-dihydroxybenzamide (Table S1D-G). Unexpected, based on previous successful matrix compounds, the 1,3-substitution of dihydroxybenzene produces higher charge states than 1,4-dihydroxybenzene using acidified bovine insulin (Figure S2).

Results were also obtained for linear conjugated matrix compounds carrying two functional groups (Table S1P, Figure S2B) including mesaconic acid ([2E]-2-methyl-2butenedioic acid) that produces up to +6 charges on acidified bovine insulin (MW 5731). However, two functional groups are not a requirement for producing highly charged ions as can be seen in case of 2,4-hexadienoic acid (Figure 3I.a). With only one carboxyl group, this matrix produces up to +12 charges on ubiquitin. A temperature study using mono-methyl fumarate ([E]-2-butenedioic acid hydrogen 1-methyl ester) as matrix shows that multiply charged ions of acidified bovine insulin can be observed as low as $50{ }^{\circ} \mathrm{C}$ (Figure S3). Further, succinic acid (butanedioic acid), a fully saturated matrix compound (Figure 3I.b) with two carboxylic acid groups, produces abundant, highly charged ions. Thus, neither aromaticity nor conjugation is a requirement for ion formation. 

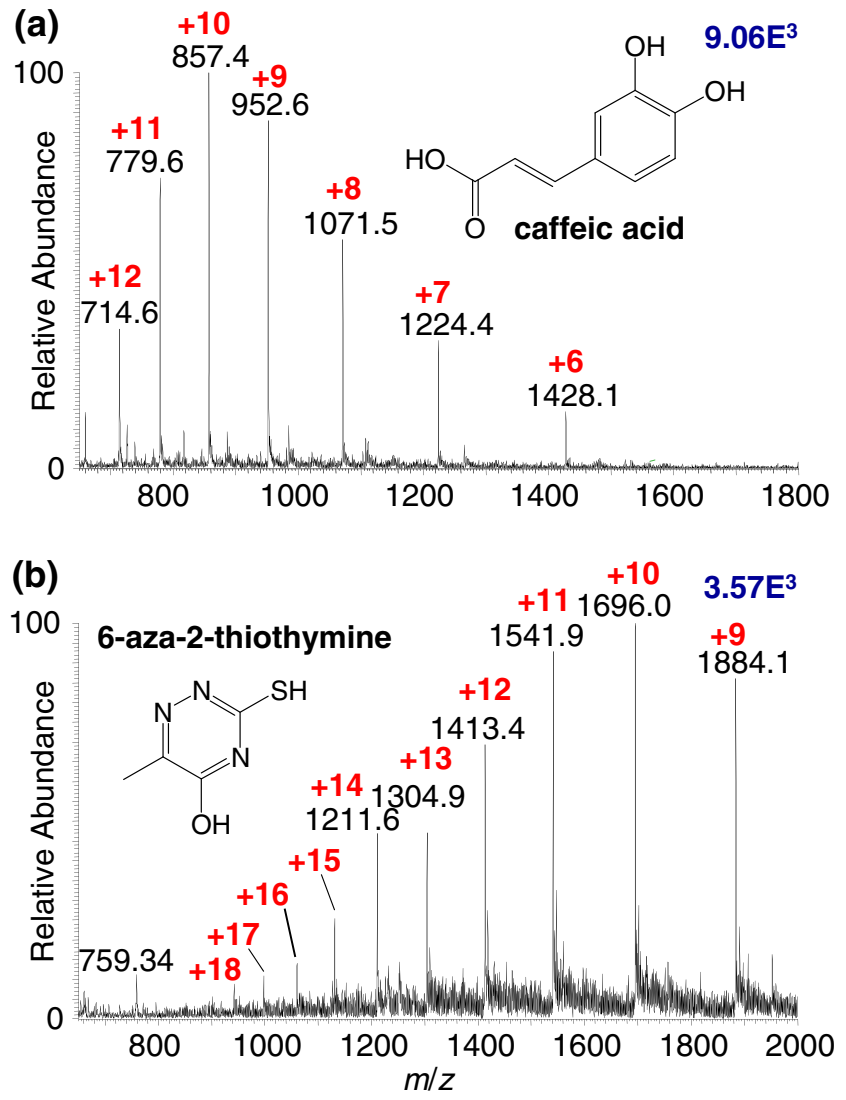

Figure 1. MAll mass spectra of MALDI matrices (a) caffeic acid matrix and ubiquitin (MW 8560) and (b) 6-aza-2thiothymine matrix and myoglobin (MW 16,952) using solvent-based sample preparation and acquired on the LTQ Velos mass spectrometer at $450{ }^{\circ} \mathrm{C}$ inlet capillary temperature

Matrix material based on thermal initiators (Scheme 4, Table S1R) used in polymer chemistry to initiate polymerization by decomposing into radicals and a good leaving group (e.g., $\mathrm{N}_{2}$ in 4,4'-azobis[4-cyanovaleric acid]), provide high abundance ions with charge states up to +13 for ubiquitin (Figure 3II.a). This thermal initiator carries $-\mathrm{COOH}$ and $-\mathrm{CN}$ functional groups. The initiator 2,2'-azobis(2-methylpropionitrile) (AIBN) bears no proton donating or electron withdrawing functional groups and surprisingly produces highly charged ions from ubiquitin if acid is added to either the matrix solution (e.g., with $1 \% \mathrm{AA}$ ) (Figure 3II.b) or the analyte (e.g., ubiquitin with $0.1 \% \mathrm{FA}$ or $1 \% \mathrm{HCl}$ ) (Figure S7).

Other aromatic compounds tested (e.g., phenol and 4trifluoromethyl phenol) as well as cyclic non-aromatic structures (e.g., 2-nitrocyclohexanol, 1,4-cyclohexane dimethanol, and 1,3-cyclohexanediol) have low melting points so that matrix evaporation is too rapid for solvent evaporation without matrix evaporation. However, solvent-free sample preparation is applicable to these samples (Figure S4 and Table S1E, H, O) because the solvent evaporation step in the presence of the volatile matrix is omitted. As is the case with the better matrices using solvent-based sample preparation, solvent-free sample preparation (e.g., 4-trifluoromethyl phenol) provides high ion abundance and little to no chemical background. Astonishing ion abundance using 2NPG matrix is observed with charge state +4 of angiotensin I using solvent-free sample preparation (Figure S4A); solvent-based sample preparation produces +3 as the base peak. Further, solvent-free sample preparation produces multiply charged ions with matrices having sulfonic acid or sulfonate functional groups (Table S1I) that fail to produce results using the common solvent-based sample preparation protocol developed for LSI. We attribute this to solubility restrictions in 50:50 ACN:water. For a number of matrices, using solvent-free sample preparation (Figure S4), singly charged ions are also detected, in addition to the multiply charged ions, and some basic MALDI matrices (e.g., 1,5diaminonaphthalene, 1,8-bis(dimethylamino)naphthalene, and 9-aminoacridine) only form +1 ions (Figure S4A). This observation is in accord with previous solvent-free studies using 2,5-DHAP and 2,5-DHB [22, 66]. This study demonstrates that compounds deemed not to work as matrices may be related to how the sample was prepared and not related to structural elements.

Matrices were employed that performed well applying the solvent-free sample preparation method in analyzing small proteins. Using matrix materials that have lower melting points (e.g., cis,cis-1,3,5-cyclohexanetriol dihydrate and 4trifluoromethyl phenol), abundant multiply charged ubiquitin ions are observed (Figure 4) similar to solvent-based sample preparation. Interestingly, 2-NPG, a well performing matrix in solvent-based sample preparation [31, 94, 95] and as noted above for angiotensin I using the solvent-free methods, only produces highly charged ions in low abundance with ubiquitin using the solvent-free method (Figure S4A). Contrary to the better performing matrices using solvent-free analysis, the 2-NPG matrix has a relatively high melting point of 189 to $193{ }^{\circ} \mathrm{C}$. This suggests that the matrices with lower melting points efficiently form a matrix:analyte solution in the solid state prior to the ionization and mass analyses which is in good agreement with previous solvent-free work [53, 66, 84, 90, 107-110]. The matrix 4-trifluoromethyl phenol, having a melting point of only $46{ }^{\circ} \mathrm{C}$, was found to produce exceptional ion abundance of ubiquitin at $50{ }^{\circ} \mathrm{C}$ using solvent-free preparation (Figure 4II.b).

Gallic acid (3,4,5-trihydroxybenzoic acid), 2,4,6-trihydroxybenzoic acid, and 2,3,4-trihydroxybenzoic acid produce high charge state ions of ubiquitin (Figure S2A). However, the methoxylated derivatives, 3,4,5-trimethoxybenzoic acid and 2,4,6-trimethoxybenzoic acid, produce notably higher abundance charge states when acidified (Figure S7) but dithranol (1,8,9-trihydoxyanthracene) provides poor results when acidified. Anthracene-9-carboxylic acid and 9,10-dinitroanthracene (Figure S2A) show abundant multiply charged ions, whereas, anthracene produces multiply charged ions (Figure S7) only when acidified, demonstrating that the presence of carboxylic acid and nitro groups enhance the ionization. Ferulic acid (3-(4-hydroxy-3- 
(a) Carboxylic acids<smiles>COc1cc(O)cc(O)c1C(=O)O</smiles>

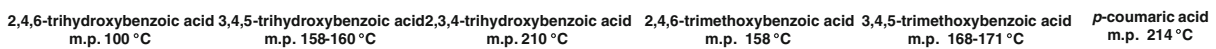

$\begin{array}{lll}\text { (b) Acetophenone } & \text { (c) Benzaldehydes }\end{array}$

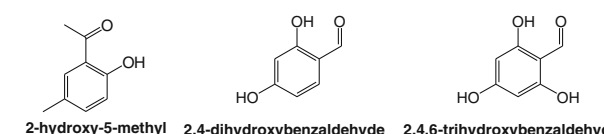

$\begin{array}{cc}\text { 2-hydroxy-5-methyl } & \text { 2,4-dihydroxybenzaldeh } \\ \text { acetophenone } & \text { m.p. } 135-137^{\circ} \mathrm{C}\end{array}$

acetophenone

$$
\text { m.p. } 45-48^{\circ} \mathrm{C}
$$<smiles>CC(C)C(=O)c1cc(O)cc(O)c1</smiles>

3,5-dihydroxybenzamide

$\mathrm{O}^{\mathrm{O} \mathrm{CH}_{3}}$

$\overbrace{\mathrm{OCH}_{3}}$

1,4-dihydroxy-

m.p. $158-162{ }^{\circ} \mathrm{C}$

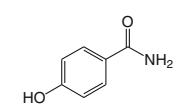

4-hydroxybenzamide
m.p. $161-162{ }^{\circ} \mathrm{C}$

m.p. ${ }^{161-162}$

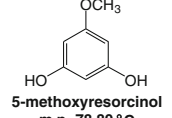

m.p. $78-80^{\circ} \mathrm{C}$

f) Nitro compounds

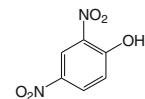

2,4-dinitrophenol

phenol
m.p. $40-43^{\circ} \mathrm{C}$<smiles>COc1ccc([N+](=O)[O-])cc1O</smiles>

OH

m.p. $195^{\circ} \mathrm{C}$

(d) Benzamides

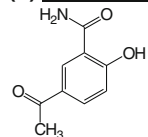

acetylsalicylamide m.p. 220-222 ${ }^{\circ} \mathrm{C}$

e) Phenols/Alcohols
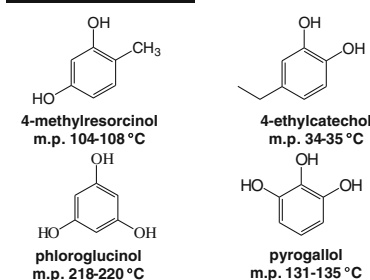

pyrogallol
m.p. $131-135^{\circ} \mathrm{C}$

(OH

4,6-dinitropyrogallol
m.p. 209-211

OH

2-nitroresorcino

4-nitroguaiacol
m.p. $99-104^{\circ} \mathrm{C}$

m.p. $142^{\circ} \mathrm{C}$
m

$\mathrm{OH} \mathrm{NO}_{2}$

p-nitrobenzyl alcohol

4-nitrophenethyl alcohol
m.p. $62-64^{\circ} \mathrm{C}$

p-nitrobenzyl alco
m.p. $92-95^{\circ} \mathrm{C}$

(g) Cyano compounds
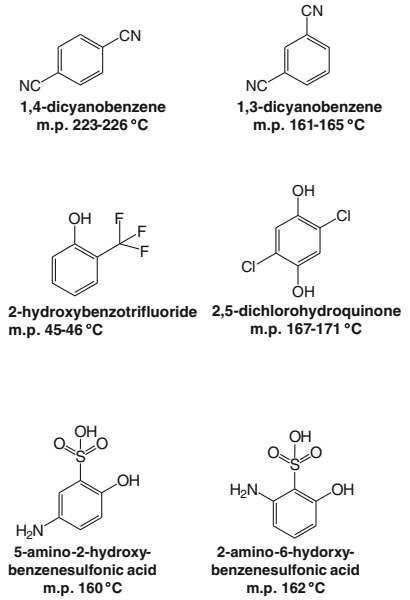

${ }^{2}$

3-nitrophenethyl alcoh

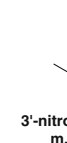<smiles>CC(=O)c1cccc(O)c1</smiles>

-nitroacetophenone
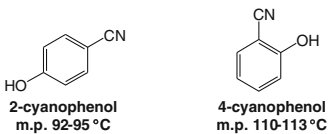

4-cyanopheno
m.p. $110-113^{\circ} \mathrm{C}$
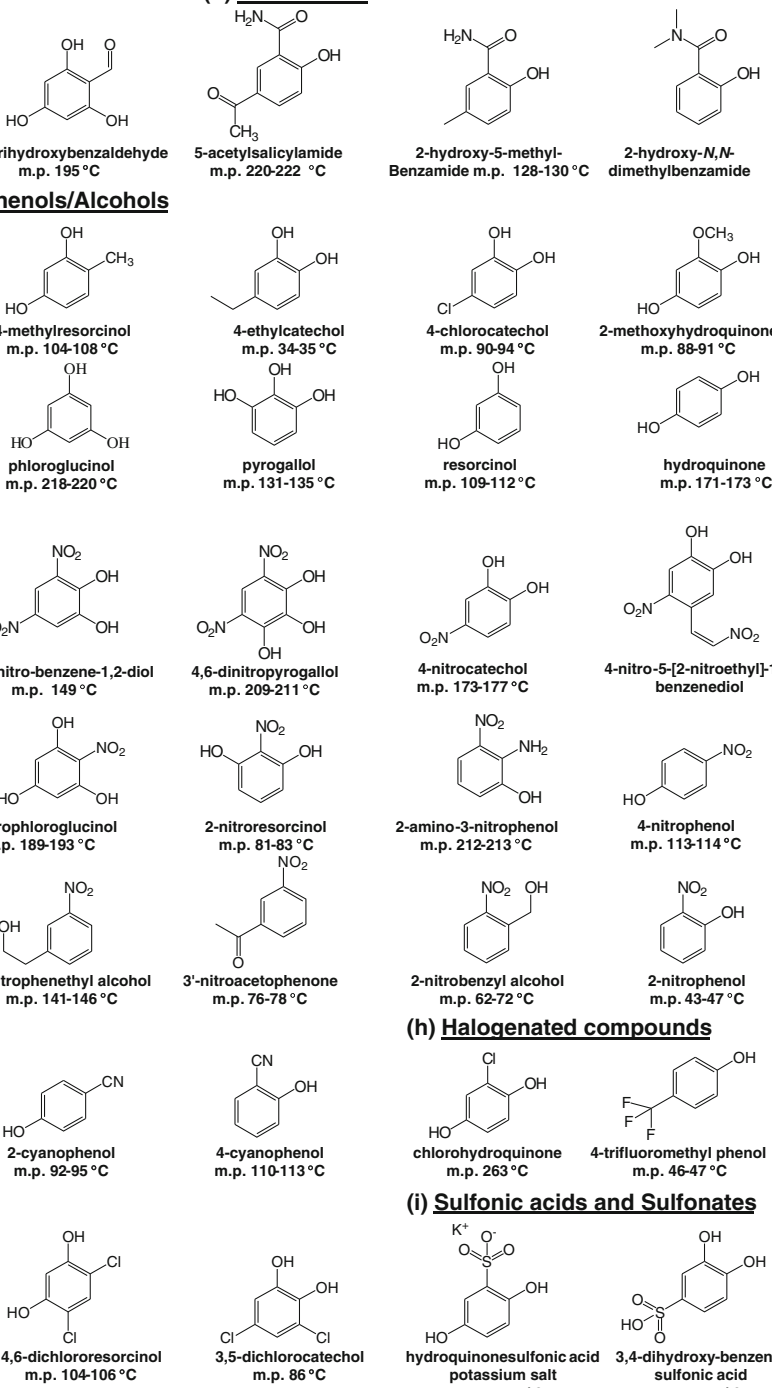

2-hydroxy-5-methyl-
2-hydroxy-N,N-
dimethylbenzamide

(a)

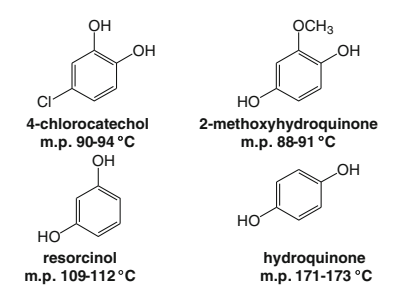

OH<smiles>O=[N+]([O-])CCc1cc(O)c(O)cc1[N+](=O)[O-]</smiles>

4-nitrocatechol
m.p. $173-177^{\circ} \mathrm{C}$

4-nitro-5-[2-nitroethyl]-1,2-
benzenediol

$\mathrm{NOH}_{\mathrm{OH}}^{\mathrm{NH}_{2}}$

4-nitrophenol

-amino-3-nitropheno

m.p. $113-114^{\circ} \mathrm{C}$
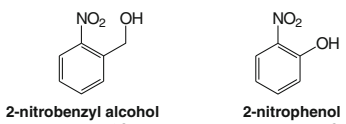

$\begin{array}{ll}\text { 2-nitrophenol } & \\ \text { m.p. } 43-47^{\circ} \mathrm{C}\end{array}$

(h) Halogenated compounds

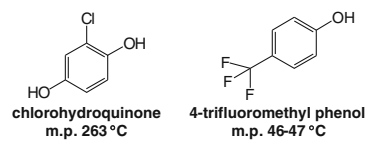

(i) Sulfonic acids and Sulfonates

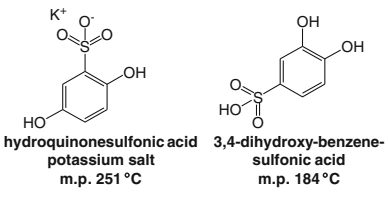

$\mathrm{Ca}^{2+} \mathrm{O} \underset{\mathrm{S}=\mathrm{O}}{\mathrm{O}=\mathrm{O}}$ (j) Amines
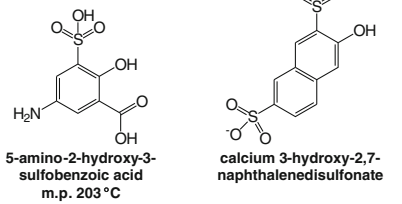

2,5-diaminohydroquinone-
(dihydrochloride)<smiles>Nc1ccccc1O</smiles>

2,3-diaminopheno

Hydrazides
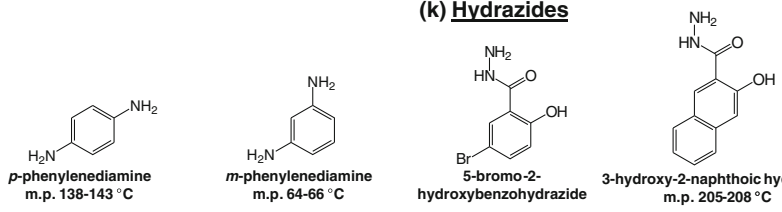

(I) Pyridine

(m) Naphthalenes
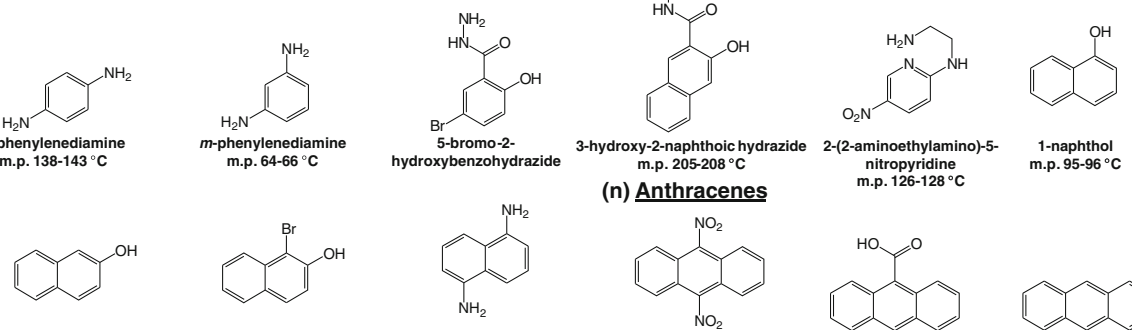

2-naphthol
m.p. $120-122^{\circ} \mathrm{C}$

1-bromo-2-naphthol
m.p. $78-81^{\circ} \mathrm{C}$ m.p. 205-208 ${ }^{\circ} \mathrm{C}$

(n) Anthracenes

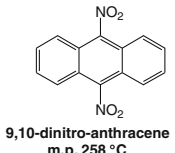

naminoethylamin
nitropyridine
(n) nitropyridine
m.p. $126-128^{\circ} \mathrm{C}$

1-naphthol
m.p. $95-96^{\circ} \mathrm{C}$
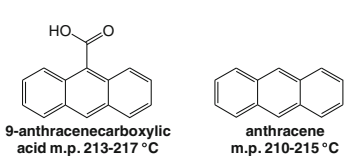

Scheme 3. Novel aromatic MAll matrices 

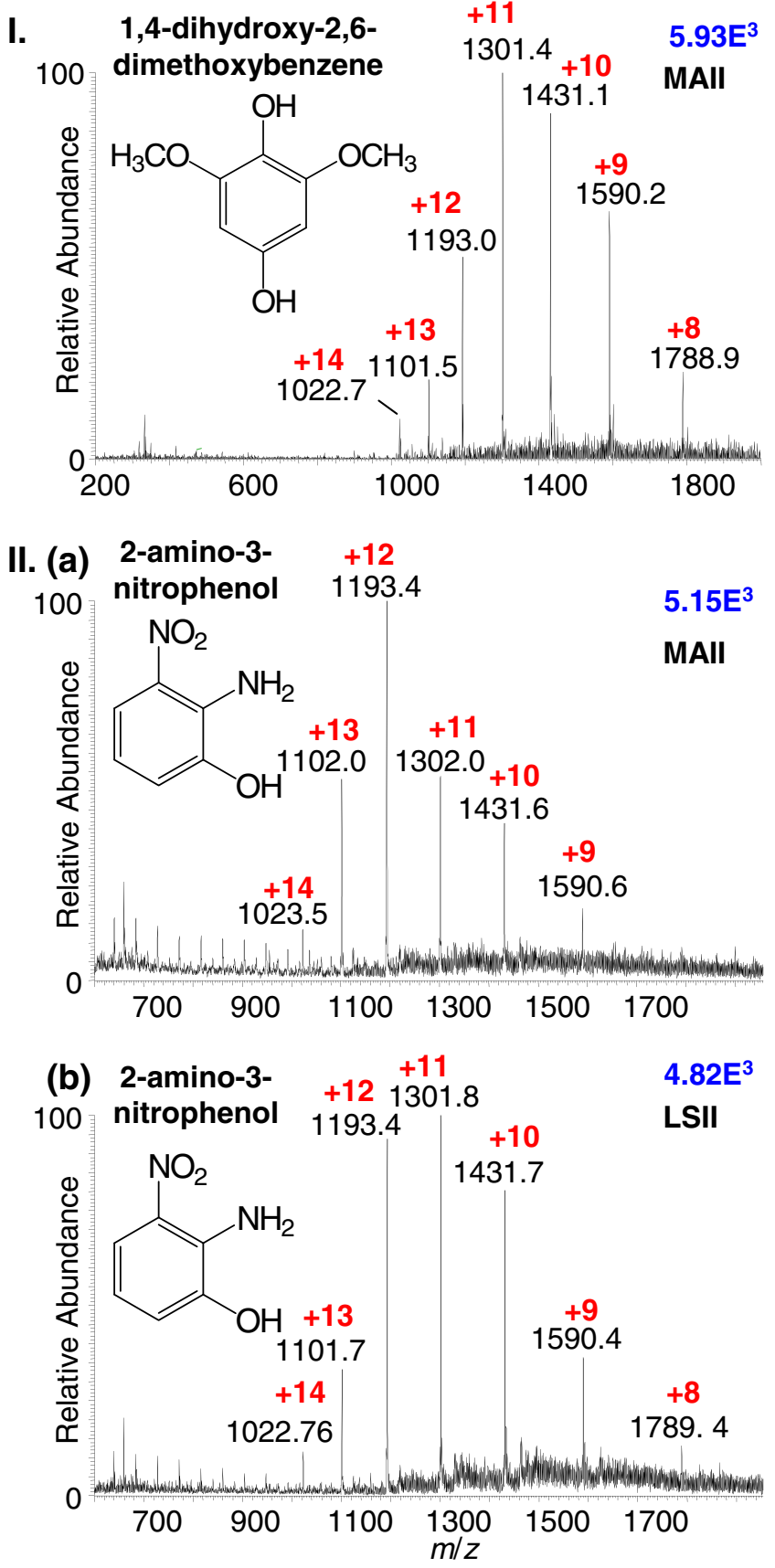

Figure 2. Mass spectra of lysozyme (MW 14,300) and novel aromatic matrices (I) 1,4-dihydroxy-2,6-dimethoxybenzene (DHDMB) matrix and (II) 2-amino-3-nitrophenol matrix using (a) MAIl and (b) LSII applying solvent-based sample preparation and acquired on the LTQ Velos mass spectrometer at $450{ }^{\circ} \mathrm{C}$ inlet capillary temperature

methoxyphenyl)-2-propenoic acid) only forms abundant multiply charged ions of ubiquitin, up to +9 , when acidified (Figure S7), but the closely related caffeic acid (Figure 1a) provides highly abundant multiply charged ions of up to +12 without acidifying. A detailed study addressing the influence of $\mathrm{pH}$ is included below.

Negative mode measurements were made with a selected set of matrices (Table S2). Basic matrices such as 2-amino- 4-methyl-3-nitropyridine (Figure 5a), 2-amino-3-nitropyridine (Figure 5b), and 4-nitroaniline are applicable for negative ionization of ubiquitin and gangliosides using an inlet temperature of $450{ }^{\circ} \mathrm{C}$ with MAII (Figure S8A). One of the better performing matrices for negative mode detection of gangliosides, 4-nitroaniline, allow the use of an inlet temperature of $150{ }^{\circ} \mathrm{C}$ (Figure S8B). At this time, too few matrices have been used in the negative ion mode to suggest structural similarities of successful matrix compounds. However, matrices with functionalities that can be protonated or deprotonated (e.g., 4-nitroaniline and 2-amino-4methyl-3-nitropyridine), operate in the positive (Figure S1C and S10) and negative mode (Figure 5, Figure S8). Basic MALDI matrices (e.g., 2-amino-3-nitropyridine and 2amino-4-methyl-3-nitropyridine) [39], provide the ability to observe negative multiply charged MAII ions of peptides, proteins, and lipids (Figure 5, Figure S8).

The utility of MAII matrices dissolved in, for example, ACN:water (50:50), referred to as dissolved MAII, were also tested in analogy to solid binary matrices described above and used in MALDI analyses [58-61]. The presence of 2,2'azobis(2-methylpropane), a non-acidic matrix, shifts the charge state distribution of ubiquitin by four charges with the most abundant at +10 (Figure 6c) relative to no matrix or acid added to the solution (SAII, Figure $6 \mathrm{~b}$ ) with the most abundant charge state +6 . Based on the chemical functionality, an increase in charge states, for example due to increased acidity, is not expected for this compound. Some supercharging reagents used in ESI [111-113] increase the charge states using dissolved MAII (Figure S14) (e.g., sulfolane) and other showed nearly the same charge state distribution (e.g., benzyl alcohol) relative to no matrix added (SAII). In case of 3-nitrobenzyl alcohol significant analytematrix adduction is observed indicating insufficient evaporation of this matrix compound at $450{ }^{\circ} \mathrm{C}$. The use of dissolved matrices directly released from the pipette tip into the mass spectrometer inlet (Scheme S1D) is one of the easiest ways to achieve ionization without the additional steps of sample deposition and dislodging by tapping (MAII) or laser ablation (LSII/LSIV) and offers the advantages to utilize high throughput liquid handling approaches in continuous flow mode [34]. The formation of the higher charge states and ion abundance (Figure 6c) permits the use of ETD fragmentation (Figure S15).

\section{Matrices Tested Using Laserspray Ionization}

Though much can be learned from MAII studies of fundamental processes for ion formation, the use of a laser to ablate the matrix:analyte likely has broader analytical utility because of the better spatial resolution that can be achieved with laser ablation [27, 32, 33]. A number of novel MAII matrices were examined for their utility as LSII matrices. These include for example 2-amino-3-nitrophenol (Figure 2II.b), DHDMB, 2-amino-3-nitropyridine, 3,5-dihydroxybenzamide, 5-bromo-2-hydroxybenzohydrazide, 3- 
(a) Non-aromatic ring

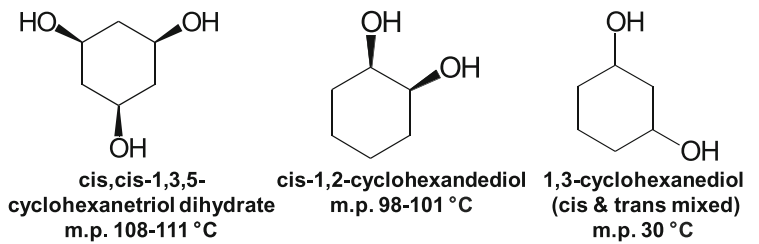

(b) Linear conjugated<smiles>CC1(C)CC(=O)C([N+](=O)[O-])C(=O)C1</smiles>

5,5-dimethyl-2-nitrocyclohexane-1,3-dione Liquid at room temperature

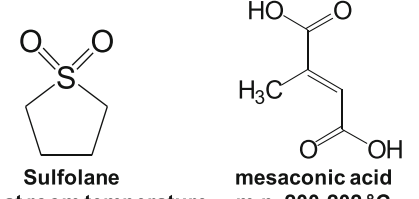

m.p. $200-202^{\circ} \mathrm{C}$
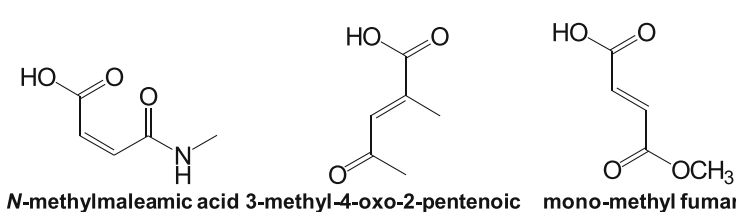

m.p. $147-150^{\circ} \mathrm{C}$<smiles>OC1CCC(O)CC1</smiles>

1,4-cyclohexanediol (cis \& trans mixed)) m.p. $98-100^{\circ} \mathrm{C}$

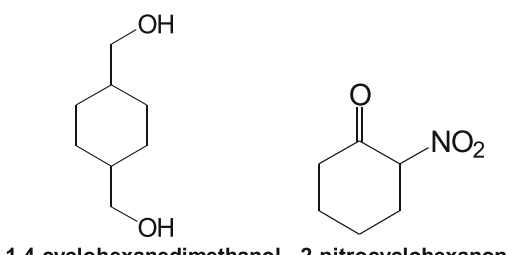

1,4-cyclohexanedimethanol 2-nitrocyclohexanone m.p. $31.5^{\circ} \mathrm{C}$ m.p. $39-43{ }^{\circ} \mathrm{C}$
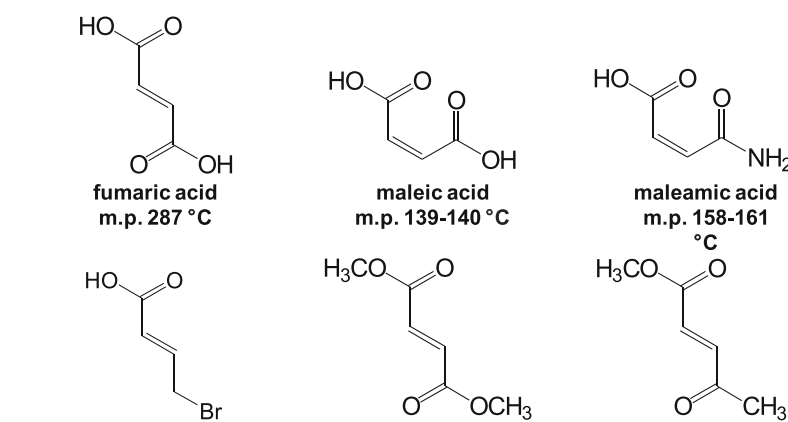

dimethyl fumarate m.p. $102-106^{\circ} \mathrm{C}$

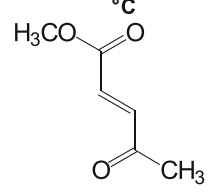

methyl 4-oxo-2-pentenoate m.p. $60^{\circ} \mathrm{C}$

(c) Linear nonconjugated
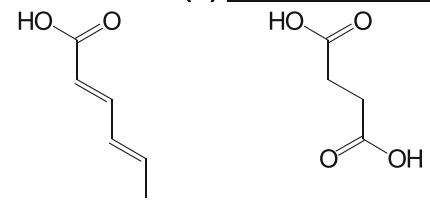

\section{2,4-hexadienoic acid} m.p. $132-135^{\circ} \mathrm{C}$

succinic acid
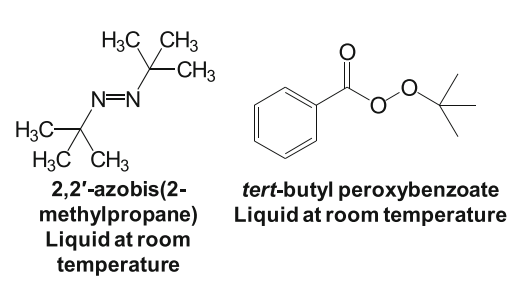

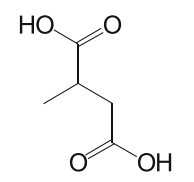

methylsuccinic acid m.p. $115-116^{\circ} \mathrm{C}$<smiles>O=C(O)CC(=O)O</smiles>

malonic acid m.p. $135-136^{\circ} \mathrm{C}$

(d) Thermally labiles acid

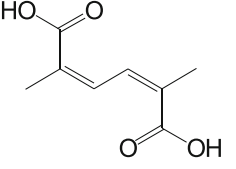

cis,cis-2,5-dimethylmuconic

Scheme 4. Novel nonaromatic and linear MAll matrices

hydroxy-2-naphthoic hydrazide, 2-amino-4-methyl-3-nitropyridine, succinic acid, and methyl trans-4-oxo-2-pentenoate (Figure S6, S10). Nearly all of these compounds provide very similar results without and with use of a laser judging by the charge state distributions using the same inlet temperature. Based on previous results this is expected because the function of the laser in LSII is to ablate the matrix so that some part of the ablated material enters the inlet for subsequent ionization. Temperature studies also follow the same trend as in MAII as described above and previously observed for LSI $[23,28]$. For example, the common MALDI matrix, salicylamide, produces abundant multiply charged ions of acidified bovine insulin at temperatures as low as $50^{\circ} \mathrm{C}$ (Figure S10B). In some cases, signals for matrix clusters are observed and decrease with increasing inlet temperature both in MAII and LSII.

MAII matrices that work poorly, if at all, for LSII applications include liquid and sticky compounds such as pyrogallol (1,2,3-trihydroxybenzene), resorcinol, monomethyl fumarate, and fumaric acid (2-butenedioic acid). Some of these matrices have a notable low melting point (e.g., 2hydroxy-5-methylacetophenone, $45^{\circ} \mathrm{C}$ ) so that the ablation with a laser in TG (Scheme 1a) has been difficult because of the morphology. Perhaps most surprising, LSII results for linear unsaturated compounds, such as methyl trans-4-oxo-2-pentenoate produces up to +5 charge state ions of bovine insulin and saturated compounds, such as succinic acid produces up to +6 charge state ions (Figure S10).

The result of MAII matrices that work as LSII matrices (Figure S10A) and do not bear any aromatic functionality or even conjugation was unexpected. Therefore, an additional set of experiments were performed using 2,5-DHAP, 2NPG, and methylsuccinic acid matrices, respectively, with the laser aligned $180^{\circ}$ (TG), as well as $0^{\circ}$ and $\sim 45^{\circ}$ (RG) relative to a collection surface at the position of the mass spectrometer inlet. Microscopy of the collection surface was 

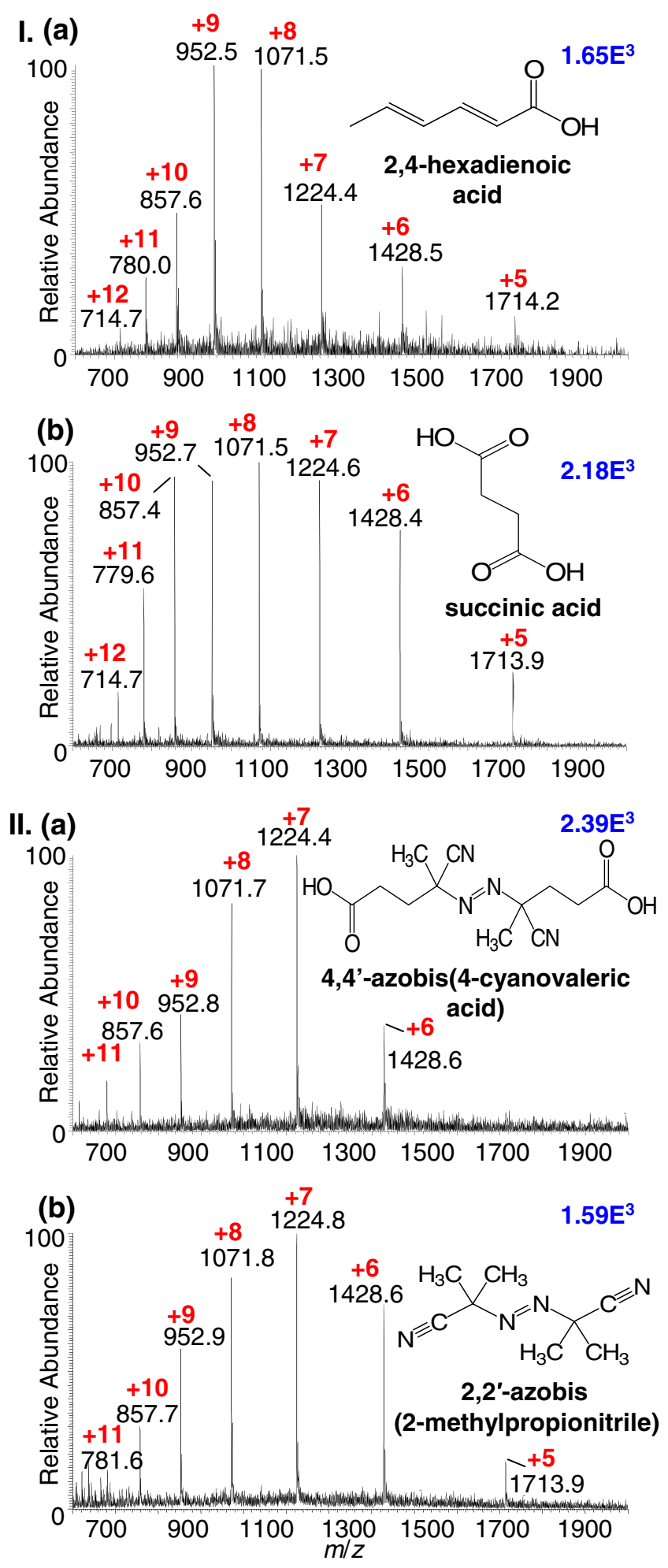

Figure 3. MAll mass spectra of ubiquitin (MW 8560) using (I) linear matrices: (a) 2,4-hexadienoic acid, (b) succinic acid, and (II) thermal initiators: (a) 4,4'-azobis(4-cyanovaleric acid) matrix, (b) 2,2'-azobis(2-methylpropionitrile) matrix acidified with acetic acid using solvent-based sample preparation acquired on the LTQ Velos mass spectrometer at $450{ }^{\circ} \mathrm{C}$ inlet capillary temperature
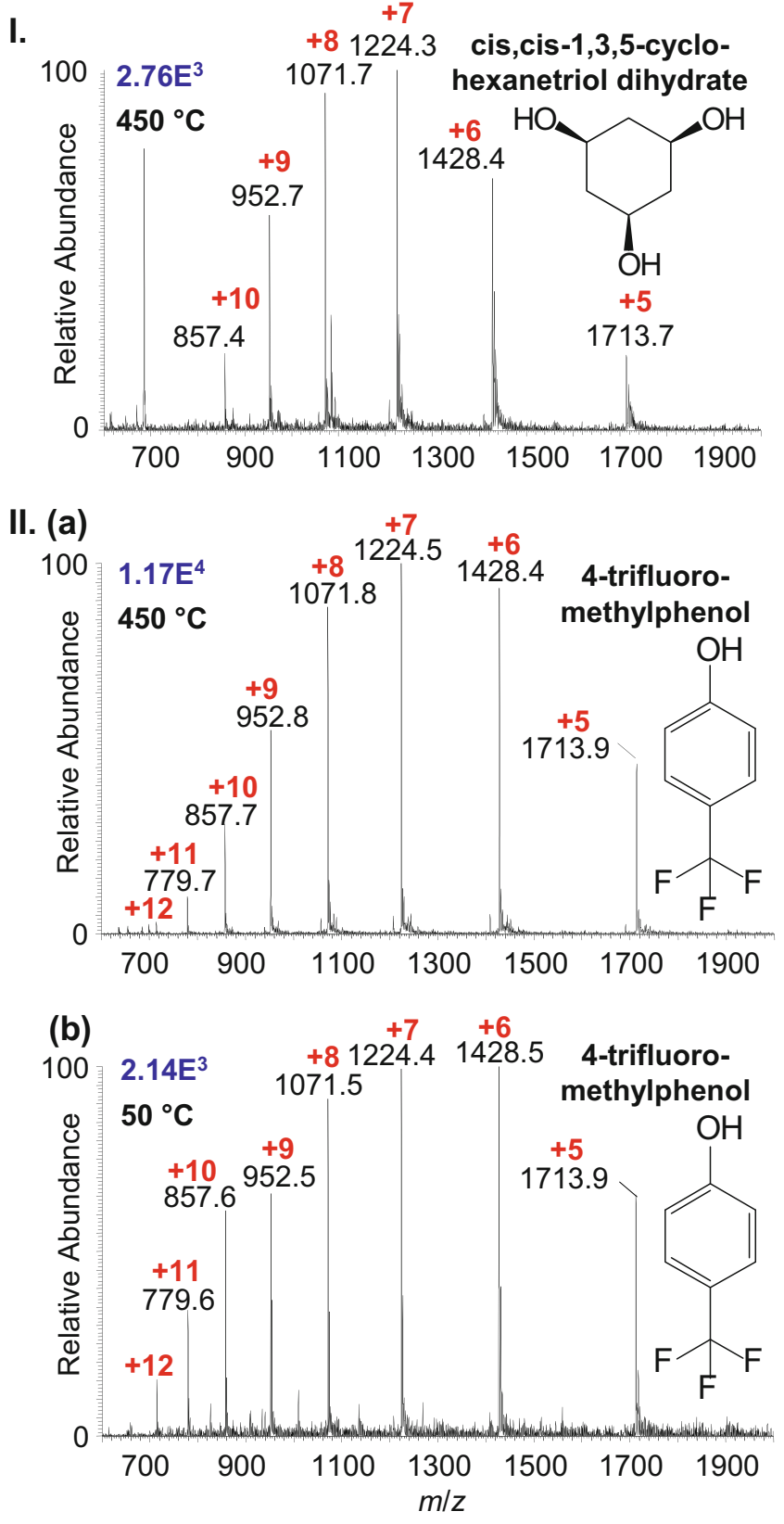

Figure 4. MAll mass spectra of ubiquitin (MW 8560) using solvent-free sample preparation with (I) cis,cis-1,3,5-cyclohexanetriol dihydrate matrix at $450{ }^{\circ} \mathrm{C}$ and (II) temperature study with 4-trifluoromethylphenol matrix at (a) 450 and (b) $50^{\circ} \mathrm{C}$ inlet capillary temperature on the LTQ Velos mass spectrometer

used to observe the results (Figure S11). Without attenuation of the laser and a single laser beam impact, complete ablation is observed where the laser beam strikes the sample $180^{\circ}$ in TG and at $0^{\circ}$ in $R G$ but less clean ablation is observed with the RG $45^{\circ}$ angle applying the same sample preparation for all three matrices in the presence of ubiquitin. The ablation diameter for 2,5-DHAP and 2-NPG is about 200 to $500 \mu \mathrm{m}$ and for methylsuccinic acid of about 50 to $100 \mu \mathrm{m}$. Thus, the methylsuccinic acid results demonstrate that with sufficient 

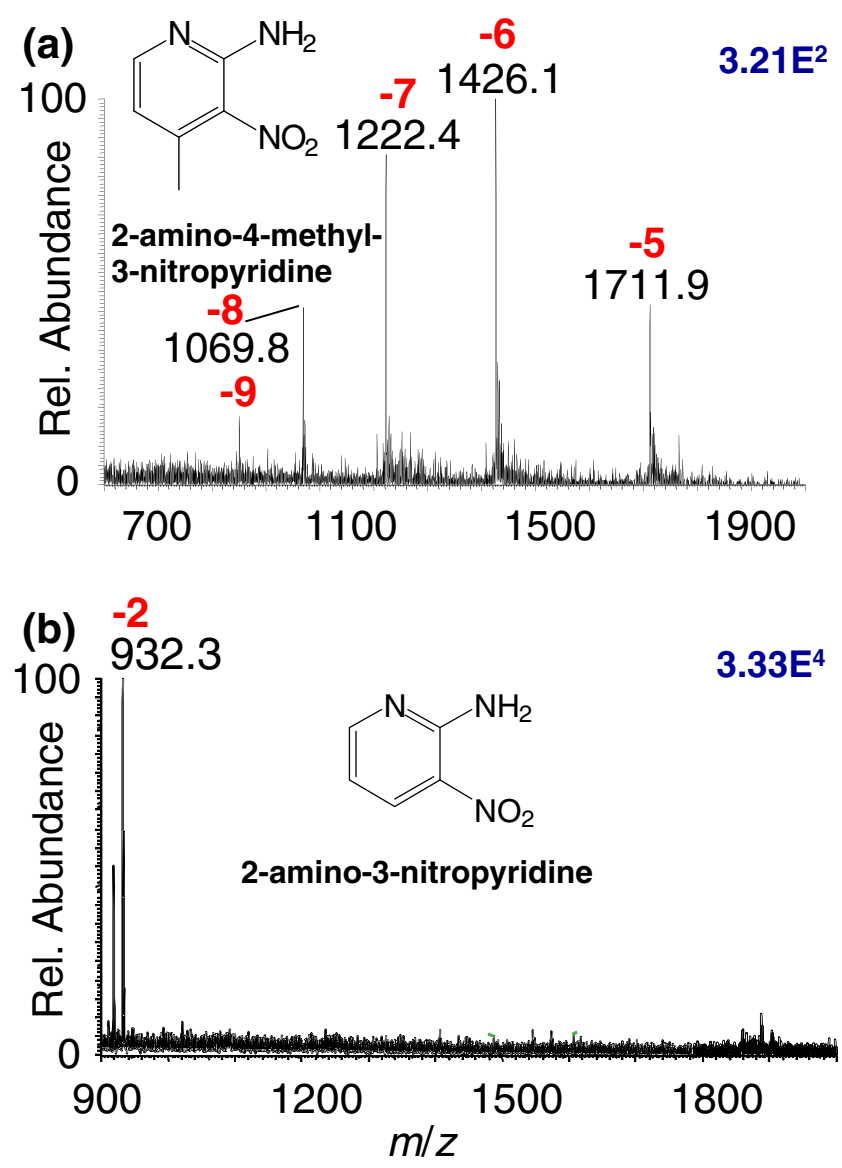

Figure 5. MAll mass spectra in negative mode measurements of (a) ubiquitin (MW 8560) and 2-amino-4-methyl-3nitropyridine matrix, and (b) ganglioside GD1 (MW 1837 and 1866) and 2-amino-3-nitropyridine matrix using solventbased sample preparation acquired on the LTQ Velos mass spectrometer at $450{ }^{\circ} \mathrm{C}$ inlet capillary temperature

laser energy, sample ablation can be induced without absorption at the laser wavelength.

The influence of acidic and basic conditions was studied by adding various acids and bases to either the analyte or matrix solutions using a variety of solvent compositions. It appears that matrices that are sufficiently acidic do not benefit from added acid (Figure S6). However, those matrices that do not carry acidic protons greatly benefit from acid addition (e.g., 2-amino-3-nitropyridine and anthracene) (Figure S6 and Figure 6a). A similar trend was not observed using more basic conditions by adding, for example, ammonium or sodium hydroxide.

Counter ions have been suggested to have importance in MALDI and ESI [14, 73, 114, 115] so their influence in positive (Figure S7) and negative mode measurements was also considered with LSII. The best acidifying results are obtained with $1 \% \mathrm{HCl} \approx 0.1 \% \mathrm{FA}>1 \% \mathrm{AA}$ and $0.1 \%$ TFA. Unexpectedly, for anthracene as matrix, the highest abundance was achieved with $1 \% \mathrm{HCl}$ added to either the analyte or the anthracene matrix solution. This indicates that the charging of the analyte must occur in solution and the
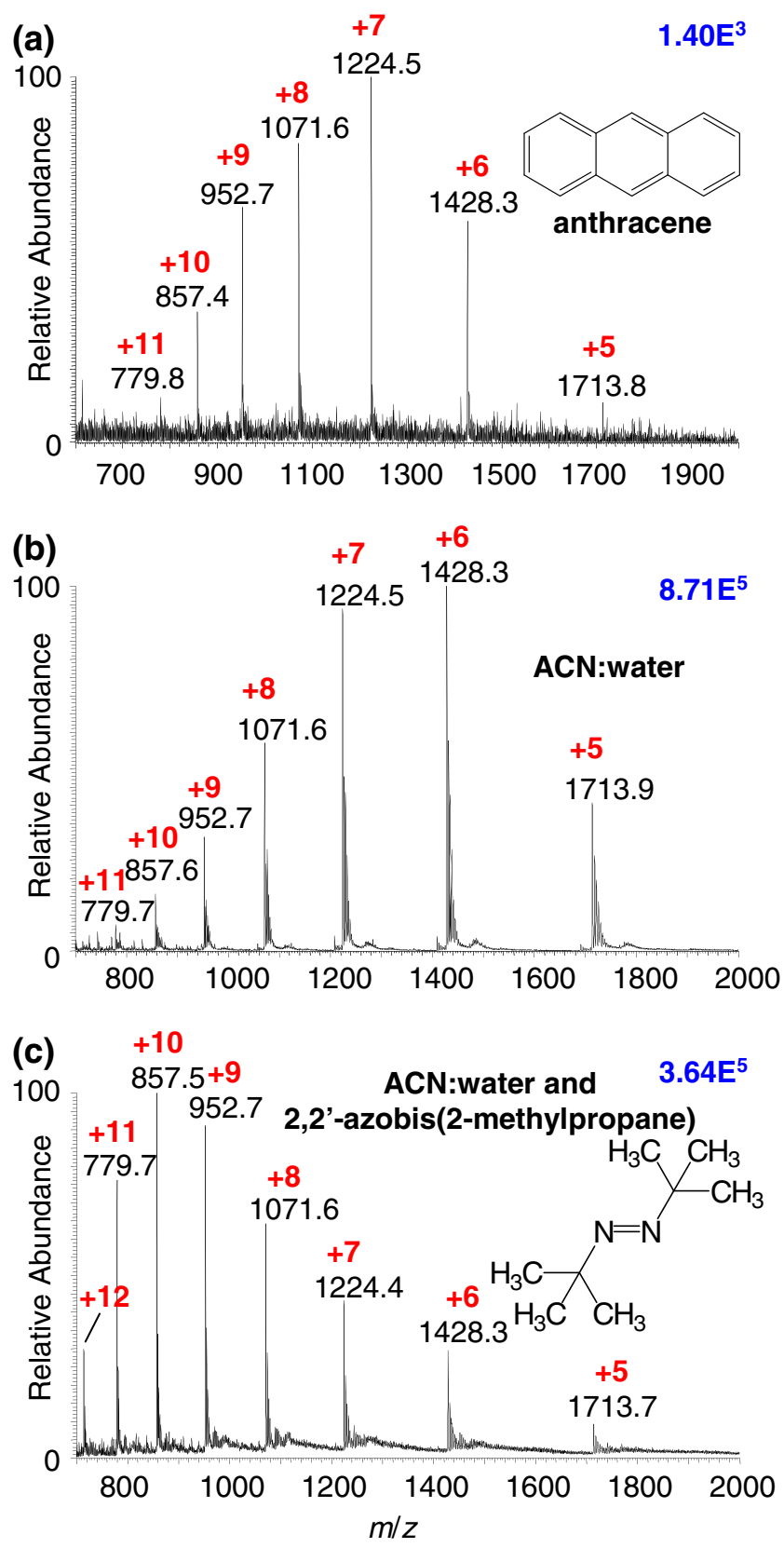

Figure 6. Mass spectra of ubiquitin (MW 8560) acquired using (a) LSIl of anthracene matrix in ACN:water acidified with $1 \%$ hydrochloric acid, (b) SAll (no matrix added to solution), and (c) dissolved MAll with 2,2'-azobis(2-methylpropane) added into the ubiquitin solution acquired on the LTQ Velos mass spectrometer at $450{ }^{\circ} \mathrm{C}$ inlet capillary temperature

matrix serves the purpose of transport into the mass spectrometer inlet. We do not see how, for example, anthracene could serve the function of counter anion. In this case, the counter anion would be the $\mathrm{Cl}^{-}$introduced when acidified. Separation of the highly charged analyte from the counter anions would likely require a means for neutralizing the anions forming gaseous compounds such as highly volatile $\mathrm{HCl}$. Notable differences are also observed 
with different solvent compositions used for dissolving the matrix, 2,5-DHAP, as well as the analyte (Figure S5). Water appears to be beneficial but not a requirement as good results are observed when acidifying an organic solution (e.g., ACN). More details regarding these mechanistic aspects are discussed elsewhere [95].

The importance of $\mathrm{pH}$ relative to the molecular weight of the analyte was studied, and using, for example, 2-amino-3nitrophenol matrix $(\mathrm{pH} \sim 4.5)$ relative to the same matrix acidified with formic acid ( $\mathrm{pH} \sim 2.5$ ) shows that the $\mathrm{pH}$ has little influence for the analyses of peptides and small proteins such as angiotensin I, bovine insulin, ubiquitin, and lysozyme (Figure S9A-D). However, for myoglobin and carbonic anhydrase, notable enhancements are observed with the addition of acid (Figure S9E, F), which permits the use of lower inlet temperature $\left(250^{\circ} \mathrm{C}\right)$; without acidifying the matrix solution prior to evaporation of the solvent, the results for the larger proteins at temperatures as high as $450{ }^{\circ} \mathrm{C}$ are relatively poor. Based on these results, addition of acid for the MAII and LSII analysis of BSA, $\sim 66 \mathrm{kDa}$, using 2-NPG as matrix, produced results with the inlet temperature as low as $200{ }^{\circ} \mathrm{C}$ [31]. We explored the use of 2,5-DHAP and 2-NPG, respectively, using the same temperature of $450{ }^{\circ} \mathrm{C}$ in the positive detection mode (Figure S16) to determine the relative sensitivity with a small protein. Using 2-NPG, $10 \mathrm{fmol} \mu \mathrm{L}^{-1}$ of bovine insulin acidified with $1 \%$ AA provides a better quality mass spectrum than $50 \mathrm{fmol} \mu \mathrm{L}^{-1}$ using 2,5-DHAP indicating an approximate fivefold increase in detection sensitivity. The 2-NPG matrix also produces highly abundant multiply charged ions at high vacuum and, therefore, we view this $-\mathrm{NO}_{2}$ containing compound as the best MAII matrix discovered in this study $[31,94,95]$.

Initial success in producing multiply charged ions by inlet ionization on a mass spectrometer commercially operated with a skimmer cone ion entrance was reported using heated inlet devices and expanded to laser ablation in vacuum using matrices with low heat requirements for desolvation [24, 25, 36, 66, 94-96]. Expanding inlet ionization to mass spectrometers without a heated inlet tube is desirable. Previous studies using 2,5-DHAP [68] also demonstrated the ability to produce abundant multiply charged ions at vacuum using the SYNAPT G2 mass spectrometer's IP-MALDI source (Scheme S1E). New matrix materials found to have analytical utility for producing multiply charged ions under vacuum conditions [94] or aid in our fundamental understanding of ion formation [95] have been published. In order to determine if the volatility of a matrix and, thus, its ability to desolvate under AP and vacuum conditions, relates to the success at low inlet temperature in inlet ionization and in producing multiply charged ions in vacuum, matrix sublimation experiments were performed at IP conditions. Using methodology described in the Experimental section, the order of fastest to slowest evaporation/sublimation at AP and IP is $2-\mathrm{NPG}>2,5-\mathrm{DHAP}>2,5-\mathrm{DHB}>\mathrm{CHCA}$ and $\mathrm{SA}$ (Figure S17). Of these compounds, only 2-NPG and 2,5-DHAP produce abundant multiply charged ions by laser ablation at
IP and 2,5-DHB requires higher inlet temperatures at AP. This finding is in support of our working hypothesis that matrix evaporation/sublimation is important for obtaining the naked multiply charged analyte ions.

Despite exceptional performance that some of the compounds tested show as MAII and LSII matrices, the majority of these matrices did not produce ions in vacuum. Perhaps the best example is DHDMB that is substituted at the identical positions as 2-NPG and produces multiply charged ions of acidified bovine insulin even at low mass spectrometer inlet temperature of $50{ }^{\circ} \mathrm{C}$ (Figure S3) identical to 2-NPG [95]. However, the functionalities are different between these two easily desolvated MAII matrices (DHDMB: two OHs and two OMe, and 2-NPG: one $\mathrm{NO}_{2}$ and three $\mathrm{OHs}$ ), and so are the results at vacuum. However, visual ablation was not observed for DHDMB in vacuum when lower laser power was employed, but at high laser power ablation occurred without observation of singly or multiply charged ions. Thus, ablation without strong absorption of the laser energy was insufficient for ion formation with DHDMB under vacuum conditions demonstrating insufficient matrix evaporation under vacuum conditions (Scheme 1b), despite the low temperature requirements using inlet technology (Scheme 1a) for this matrix (Figure S3).These results indicate that other parameters must have critical roles at vacuum ionization as discussed in the accompanying paper relative to the driving forces superheating and bubble formation [95], especially in the absence of an efficient heating source.

Some of the matrices evaporated/sublimed too rapidly in vacuum, a common observation in vacuum MALDI [116, 117]. For this and related reasons, the utility of binary matrices were explored. CHCA and SA matrices produce, at inlet temperatures of $450{ }^{\circ} \mathrm{C}$, barely any ions using MAII or LSII (Figure S12A). However, with $5 \% 2-\mathrm{NPG}$ and $95 \%$ CHCA abundant highly charged ions are observed. The charge state distribution is lower relative to pure 2-NPG matrix; pure 2-NPG produces lysozyme ions up to +19 (Figure S12A) and the binary matrix for SA and CHCA with $5 \% 2-\mathrm{NPG}$ up to +15 and +18 charges, respectively. Temperature studies of binary matrices at AP show that the inlet temperature requirements are notably lowered for SA and CHCA when $5 \% 2-\mathrm{NPG}$ is added. Consequently, binary matrices with 2-NPG are also useful at IP (Figure S12B) and LP (Figure S12C) producing multiply charged analyte ions similar to those obtained with $100 \% 2-\mathrm{NPG}$ [94]. Binary matrices extend the time before the volatile matrix component evaporates under vacuum condition, an important consideration for analyses for which longer acquisition times must be anticipated (e.g., tissue imaging $[118,119])$.

\section{Discussion}

\section{Observed Trends}

Known MALDI matrices, and hitherto unknown small molecules, comprising aromatic, nonaromatic, cyclic, or 
linear without conjugation, and conjugated structures with no other functionality, produce multiply charged ions using MAII with an inlet temperature of $450{ }^{\circ} \mathrm{C}$. Initially, a trend to higher charge states and abundance with more acidic matrices was observed [67]. The new aromatic MAII matrices partially follow this trend (e.g., 2-NPG) [31], but this is not the case with, for example, DHDMB. Both structures have at least two OHs, one in ortho (DHDMB) and the other in para-substitution (2-NPG), and at least one electron withdrawing group. 2,4,6-Trihydroxyacetophenone also has the same substitution positions, but the results are not as good (Figure S1C). Similarly, phloroglucinol (1,3,5trihydroxybenzene) and 5-methoxyresorcinol (5-methoxy1,3-benzenediol) (Table S1E) do not produce multiply charged ions, and structures with identical substitution positions, 3,5-DHB (Figure S1A) and 3,5-DHAP (Figure S1B) produce poor results relative to other DHB and DHAP isomers. However, pyrogallol (1,2,3-trihydroxybenzene) with the same 1,3,5-substitution pattern but without the carboxylic acid or acetophenone functionality produces good results (Figure S2A). Structurally similar compounds such as 2-nitroresorcinol (2-nitro-1,3-dihydroxybenzene) (Figure S2A), 2-amino-3nitrophenol (Figure 2II, Figure S9), other DHB isomers and DHAP isomers (Figure S1A, B) produce average to good results. However, adding an additional hydroxyl group para to the nitro group of, for example 2-nitroresorcinol, produces excellent results (2-NPG, Figure S2A) [31, 94].

Based on the ion abundance of multiply charged peptide and protein ions in the positive detection mode [94] the best performing matrix discovered in this study is $2-\mathrm{NPG}$, however, not all nitro containing compounds work well. It has been noted that the nitro functional group has properties similar to a carboxylic acid group [120, 121]. Using the structure of 2-NPG as a starting point and examining data from other useful MAII matrices one may find fuzzy commonalities between some of the better MAII matrices. For example, groups in the para position in addition to at least one further functional group, frequently electron withdrawing (e.g., 2,5-DHB, 2,5-DHAP, DHDMB, 2-NPG, and 3,5-dinitro-benzene-1,2-diol) (Figure 2, Figure S1, S2A, Table S1A, B, E, F) seem important. Perhaps a clearer trend is that the more $\mathrm{OH}$ groups produce higher analyte ion abundance, which is best seen with the comparison of nitro compounds with increasing numbers of -OH groups (Figure S2A); however, more heat needs to be provided for similar analyte ion abundances (Table S1F). Possibly a good leaving group is important [99].

There are exceptions to any structural commonalities observed at this point. For example, anthranilic acid performs well (Figure S1C), as does 1,3-dicyanobenzene which has no $-\mathrm{OH}$ groups, but produces abundant multiply charged ions in the positive mode when the analyte solution is acidified with $0.1 \%$ FA (Figure S7). There are no acidic hydrogen atoms with this latter matrix, and so it might be assumed that analyte and residual solvent contribute the protons required for analyte ionization. Loss of volatile components by thermal decomposition of the matrix (e.g., nitro and azo compounds) has the potential to increase ionization through rapid bubble formation [95]. This is supported by the finding that polymer initiators such as 4,4'azobis(4-cyanovaleric acid) $\left(\mathrm{HOOCCNCH}_{3} \mathrm{CH}-\mathrm{N}=\mathrm{N}-\right.$ $\left.\mathrm{CHCNCH}_{3} \mathrm{COOH}\right)$ produces multiply charged analyte ions in MAII (Figure 3II.a, Table S1R); however, 2,2'-azobis(2methylpropionitrile) $\left(\mathrm{NC}\left(\mathrm{CH}_{3}\right)_{2} \mathrm{C}-\mathrm{N}=\mathrm{N}-\mathrm{C}\left(\mathrm{CH}_{3}\right)_{2} \mathrm{CN}\right)$ does not, unless the matrix:analyte mixture is prepared from an acidic solution (Figure 3II.b). This may indicate that the loss of nitrogen gas from decomposition of the thermally labile matrix is important, but seems more clearly to indicate the importance of pre-charging the analyte.

The necessity for decomposition of the matrix to perform well as ionization medium must be ruled out based on the outcome of the anthracene experiments that shows excellent analyte ion abundance when acidified solutions, even with $\mathrm{HCl}$, were used at inlet temperatures of $450{ }^{\circ} \mathrm{C}$ (Scheme 1a). As long as a proton source from a variety of acids is provided to the solution prior to crystallization of the matrix and analyte, good analyte ion abundances are obtained if sufficient heat is supplied. Obstruction, gases, and $\mathrm{rf}$ voltages can also be of a constructive means of matrix evaporation from clusters (Figure S13) and may be efficient means for mass spectrometers absent of a heated inlet.

Some of the trends noted above may be related to our initial compound selection. In attempts to expand the matrices available to LSII, several matrices initially used in MALDI, as well as DHB and DHAP isomers, were tested. Based on this predetermined set of compounds, 3,5-DHB, 3,5-DHAP, SA, $\mathrm{CHCA}$, and dithranol produced poor results even at $450{ }^{\circ} \mathrm{C}$ whereas the other isomers of DHB and DHAP as well as caffeic acid worked reasonably well in producing multiply charged ions at this temperature. As with MALDI, the 2,5-isomers of DHB and DHAP worked the best in producing multiply charged ions in MAII/LSII [22]. Based on prior work, we speculated that hydroxyl groups on a benzene ring that are in the ortho- or para- positions relative to an electron withdrawing group would be a good matrix while substitution in the 3,5position is detrimental. Interestingly, most of the compounds we expected might be good matrices produced reasonably abundant multiply charged ions at an inlet temperature of $450^{\circ} \mathrm{C}$, but so also did the compounds we thought would not be good LSII matrices.

In order to eliminate selection based on absorbance of the matrix at the laser wavelength, MAII, which does not require a laser, was used to test matrices. Upon expanding the tested compounds to those with poor absorbance at the $337 \mathrm{~nm}$ of a nitrogen laser, but having at least one hydroxyl group along with an electron withdrawing group, we discovered that most of these compounds provided multiply charged ions even absent an aromatic ring. Further testing demonstrated that linear or cyclic structures, even without unsaturation in the carbon structure, provided multiply charged ions of peptides and small proteins. These surprising results led to testing compounds that have no acidic protons, such as 1,4- 
dicyanobenzene, 1,3-dicyanobenzene, dimethyl fumarate, anthracene, and 2,2'-azobis(2-methylpropionitrile). These matrices produce multiply charged ions if the solution from which they are dried was first made acidic.

\section{Discussion Related to Observed Trends}

No structural element(s) for a MAII matrix seem essential except the need for at least one acidic proton, which, as noted above, can be circumvented by adding acid to the solution from which the matrix and analyte was dried. Based on minimum ion abundance, 137 out of 176 matrix compounds analyzed on the LTQ Velos with the inlet temperature set to $450{ }^{\circ} \mathrm{C}$ are considered MAII matrices. High abundance analyte ions are produced by 56 of these compounds. Out of these 56 better, 35 produced significant ion abundances also at $300{ }^{\circ} \mathrm{C}, 26$ at $200{ }^{\circ} \mathrm{C}$, and six at $50{ }^{\circ} \mathrm{C}$. A number of compounds tested with LSII employing a nitrogen laser produced multiply charged ions even though some had weak absorption at the laser wavelength, suggesting that ablation in some cases may be a result of acoustic desorption from the glass microscope slide. Thus, known MALDI matrices and hitherto unknown small molecules, comprising aromatic, nonaromatic, cyclic, or linear carbon chains with various functional groups, with and without conjugation, and even those that are conjugated, but with no other functionality, produce multiply charged analyte ions using MAII.

The best matrices discovered so far, however, have electron withdrawing groups, but the wide range of small molecule structures that act as matrices in MAII or LSII suggest that the structure of the molecule plays a secondary role relative to physical properties such as morphology of the matrix on the target plate, its propensity to evaporate, sublime, or even thermally decompose [99], as well as its ability to solvate counter anions. A matrix that forms a layer that does not ablate well in LSII or does not produce particles when tapped against the mass spectrometer inlet in MAII, will not produce ionized analyte. Similar observations have been made in MALDI where visualization of the matrix layer is often sufficient to determine if the analysis will be successful. A 'good' matrix also strongly depends on the experimental conditions of the measurement and even the mass spectrometer used. The more limited number of compounds found suitable as matrices in MALDI may be as much a function of the restrictions imposed by the experimental conditions as any single factor studied to date.

Matrices that evaporate or sublime at lower temperature also need lower inlet temperature to produce multiply charged analyte ions suggesting that the inlet temperature may be more important for desolvation of the charged matrix droplets than for charging the matrix droplets. Matrices that are too volatile cannot be directly employed under vacuum conditions, but those that have good volatility and strong absorbance at the laser wavelength, such as 2-NPG and 2,5DHAP might be useful as LSI matrices in IP-MALDI, and possibly LP-MALDI-TOF mass spectrometers. Binary matrix mixtures having a volatile LSI matrix combined with a strongly absorbing MALDI matrix such as CHCA or SA also produce abundant multiply charged analyte ions somewhat reducing the problem of too rapid sublimation/ evaporation of volatile matrices in vacuum.

Many matrix compounds that showed difficulty in proper crystallization, had poor solubility in the solvents used, and even those too volatile to remove solvent (e.g., water) were found to work well with peptides and proteins using solventfree sample preparation. Thus, 52 matrices, including phenol, 2-nitrophenol, 4-trifluorophenol, and 3,4-dihydroxybenzenesulfonic acid produced high abundant multiply charged ions under solvent-free conditions. Matrices that are liquids can be easiest employed using dissolved MAII.

Considering that 137 compounds out of 176 studies serve as MAII matrices along with the observation that matrix: analyte droplets are formed during laser ablation [28, 66], we conclude that matrix compounds serve a similar purpose as solvents in SAII and ESI. Solvents such as water and methanol produce similar multiply charged ions of peptides and proteins in inlet ionization. It is, therefore, reasonable that solid matrix materials that can fulfill certain critical properties of solvents, possibly even in the molten state, will be good matrix materials provided the morphology of the dried matrix allows particles to enter the heated inlet and evaporative processes of the matrix:analyte droplets (clusters) are sufficiently fast to release the multiply charged ions. Mechanistic considerations for matrix assisted ionization, LSI, and MALDI, are provided in an accompanying paper [95].

\section{Conclusion}

This work demonstrates that a wide variety of compounds are useful for matrix enhancement of ionization when suitable $\mathrm{pH}$ and sufficient heat or other means for desolvation of the matrix from the matrix:analyte droplets are supplied. These results when combined with similar mass spectra obtained using solvents such as water and methanol suggests that a solid matrix may serve the same purpose as a solvent in ionization. Compounds that do not have acidic protons can become useful matrices after acidifying either the analyte or matrix solution. Those matrices that have higher volatility are more likely to produce abundant highly charged ions at low inlet temperatures and some are also applicable under IP and LP conditions [31, 94, 95]. Solventfree MAII/LSII may likely be of general value for analytes and matrices where solvent-based sample preparation is challenging, as, for example, hydrophobic and solubility restricted compounds such as lipids, hydrophobic peptides, and membrane proteins as well as matrices suffering from low solubility. Many more applications may develop through the use of binary matrices. Negative mode measurements have required prohibitive amounts of sample [65, 122], so that the initial success of a number of new matrices 
providing multiply charged negative ions directly from surfaces is expected to provide opportunities for materials analyses that critically depend on negative ion formation $[33,39]$. As has been reported before [94], different matrices show different propensities for different analytes (e.g., synthetic polymers) and will need to be explored in more detail in future studies. The application of use of dissolved MAII matrices may provide unknown opportunities for unadulterated tissue analyses and imaging at continuous flow [34], especially in conjunction with high performance fragmentation technologies such as ETD. Continued studies in the relationship of matrix, vacuum, thermal and laser assisted ionization for use in MS is of fundamental and practical importance $[95,123]$.

\section{Acknowledgments}

The authors gratefully acknowledge funding from Wayne State University (Schaap Graduate and Summer Dissertation Fellowships to E.D.I.; Rumble Fellowships to E.D.I. and B.W.; Summer Fellowship to C.B.L., A.LR., and C.D.M.; Schaap Faculty Scholar to S.T.), NSF CAREER 0955975, ASMS Research Award (financially supported by Waters Corporation), DuPont Young Professor Award, and Eli Lilly Young Investigator Award in Analytical Chemistry. The authors are thankful to Dr. Larsen (DuPont) for instrument access and Dr. McEwen (USP) for friendly competition.

\section{References}

1. Tanaka, K., Waki, H., Ido, Y., Akita, S., Yoshida, Y., Yoshida, T. Protein and polymer analysis up to $\mathrm{m} / \mathrm{z} 100,000$ by laser ionization time-of-flight mass spectrometry. Rapid Commun. Mass Spectrom. 2, $151-153$ (1988)

2. Karas, M., Hillenkamp, F.: Laser desorption ionization of proteins with molecular mass exceeding 10,000 daltons. Anal. Chem. 60, 2299-2301 (1988)

3. Yamashita, M., Fenn, J.B.: Electrospray ion-source-another variation on the free-jet theme. J. Phys. Chem. 88, 4451-4459 (1984)

4. Glückmann, M., Pfenninger, A., Krüger, R., Thierolf, M., Karas, M., Horneffer, V., Hillenkamp, F., Strupat, K.: Mechanisms in MALDI analysis: surface interaction or incorporation of analytes. Int. J. Mass Spectrom. 210, 121-123 (2010)

5. Fournier, I., Brunot, A., Tabet, J.C., Bolbach, G.: Delayed extraction experiments using a repulsive potential before ion extraction: evidence of clusters as ion precursors in UV-MALDI. Part I: dynamical effects with the matrix 2,5-dihydroxybenzoic acid. Int. J. Mass Spectrom 213, 203-251 (2002)

6. Knochenmuss, R.A.: Quantitative model of ultraviolet matrix-assisted laser desorption/ionization including analyte ion generation. Anal. Chem. 75, 2199-2207 (2003)

7. Knochenmuss, R.A.: Ion formation mechanisms in UV-MALDI. Analyst 131, 966-986 (2006)

8. Chang, W., Huang, L.C.L., Wang, Y.S., Peng, W.P., Chang, H.C., Hsu, N.Y., Yang, W.B., Chen, C.H.: Matrix-assisted laser desorption/ ionization (MALDI) mechanism revisited. Anal. Chim. Acta 582, 1-9 (2007)

9. Consta, S.: Manifestation of rayleigh instability in droplets containing multiply charged macroions. J. Phys. Chem. B 114, 5263-5268 (2010)

10. Ahadi, E., Konermann, L.: Molecular dynamics simulations of electrosprayed water nanodroplets: internal potential gradients, location of excess charge centers, and "Hopping" protons. J. Phys. Chem. B 113, 7071-7080 (2009)
11. Znamenskiy, V., Marginean, I., Vertes, A.: Solvated ion evaporation from charged water nanodroplets. J. Phys. Chem. A 107, 7406-7412 (2003)

12. Kebarle, P., Verkerk, U.H.: Electrospray: from ions in solution to ions in the gas phase, what we know now. Mass Spectrom. Rev. 28, 898-917 (2009)

13. Nguyen, S., Fenn, J.B.: Gas-phase ions of solute species from charged droplets of solutions. J. B. Proc. Natl. Acad. Sci. U.S.A. 104, 11111117 (2007)

14. Karas, M., Glückmann, M., Schäfer, J.: Ionization in matrix-assisted laser desorption/ionization: singly charged molecular ions are the lucky survivors. J. Mass Spectrom. 35, 1-12 (2000)

15. Karas, M., Krüger, R.: Ion formation in MALDI: the cluster ionization mechanism. Chem. Rev. 103, 427-439 (2003)

16. Knochenmuss, R.A., Zhigilei, L.V.: Molecular dynamics model of ultraviolet matrix-assisted laser desorption/ionization including ionization processes. J. Phys. Chem. B 109, 22947-22957 (2005)

17. Knochenmuss, R.A.: A quantitative model of ultraviolet matrix-assisted laser desorption/ionization. J. Mass Spectrom. 37, 867-877 (2002)

18. Jaskolla, T.W., Karas, M.: Compelling evidence for lucky survivor and gas phase protonation: the Unified MALDI analyte protonation mechanism. J. Am. Soc. Mass Spectrom. 22, 976-988 (2011)

19. Dole, M., Mack, L.L., Hines, R.L., Mobley, R.C., Ferguson, L.D., Alice, M.B.: Molecular beams of macroions. J. Chem. Phys. 49, 22402249 (1968)

20. Iribarne, J.V., Thomson, B.A.: Evaporation of small ions from charged droplets. J. Chem. Phys. 64, 2287-2294 (1976)

21. Trimpin, S., Herath, T.N., Inutan, E.D., Cernat, S.A., Miller, J.B., Mackie, K., Walker, J.M.: Field-free transmission geometry atmospheric pressure matrix-assisted laser desorption/ionization for rapid analysis of unadulterated tissue samples. Rapid Commun. Mass Spectrom. 23, 3023-3027 (2009)

22. Trimpin, S., Inutan, E.D., Herath, T.N., McEwen, C.N.: Matrix-assisted laser desorption/ionization mass spectrometry method for selectively producing either singly or multiply charged molecular ions. Anal. Chem. 82, 11-15 (2010)

23. Trimpin, S., Inutan, E.D., Herath, T.N., McEwen, C.N.: Laserspray ionization, a new atmospheric pressure MALDI method for producing highly charged gas-phase ions of peptides and proteins directly from solid solutions. Mol. Cell. Proteom. 9, 362-367 (2010)

24. Inutan, E., Trimpin, S.: Laserspray ionization (LSI) ion mobility spectrometry (IMS) mass spectrometry. J. Am. Soc. Mass Spectrom. 21, 1260-1264 (2010)

25. Inutan, E.D., Trimpin, S.: Laserspray ionization-ion mobility spectrometry-mass spectrometry: baseline separation of isomeric amyloids without the use of solvents desorbed and ionized directly from a surface. J. Proteome Res. 9, 6077-6081 (2010)

26. Laiko, V.V., Baldwin, M.A., Burlingame, A.L.: Atmospheric pressure matrix-assisted laser desorption/ionization mass spectrometry. Anal. Chem. 72, 652-657 (2000)

27. Inutan, E.D., Richards, A.L., Wager-Miller, J., Mackie, K., McEwen, C.N., Trimpin, S.: Laserspray ionization - a new method for protein analysis directly from tissue at atmospheric pressure and with ultra-high mass resolution and electron transfer dissociation sequencing. Mol. Cell. Proteomics 10, 1-8 (2011)

28. McEwen, C.N., Trimpin, S.: An alternative ionization paradigm for atmospheric pressure mass spectrometry: flying elephants from Trojan horses. Int. J. Mass Spectrom. 300, 167-172 (2011)

29. Sheehan, E.W., Willoughby, R.C.: U.S. Patent \#7060976; June 13 (2006)

30. McEwen, C.N., Larsen, B.S., Trimpin, S.: Laserspray ionization on a commercial atmospheric pressure-MALDI mass spectrometer ion source: selecting singly or multiply charged ions. Anal. Chem. 82, 4998-5001 (2010)

31. Lietz, C.B., Richards, A.L., Ren, Y., Trimpin, S.: Inlet ionization: protein analyses from the solid state without the use of a voltage or a laser producing 67 charges on BSA, $66 \mathrm{kDa}$. Rapid Commun. Mass Spectrom. 25, 3453-3456 (2011)

32. Richards, A.L., Lietz, C.B., Trimpin, S.: Imaging mass spectrometry in transmission geometry. Rapid Commun. Mass Spectrom. 25, 815-829 (2011)

33. Richards, A.L., Lietz, C.B., Wager-Miller, J., Mackie, K., Trimpin, S.: Laserspray ionization $\mathrm{MS}^{\mathrm{n}}$ and high spatial resolution tissue imaging of labile gangliosides. J. Lipid Res. 53, 1390-1398 (2012)

34. Li, J., Wang, B., Richards, A.L., Lietz, C.B., Payne, L., Inutan, E.D., Tang, 
H., Salley, S., Trimpin, S.: Laserspray Ionization (LSI)- and MatrixAssisted Inlet Ionization (MAII)-Ion Mobility Spectrometry (IMS)-Mass Spectrometry (MS) for the Analysis of Biofuels. Proceedings of the 59th ASMS Conference, Denver, CO, ThP346, June 4-9 (2011)

35. Pagnotti, V.S., Chubatyi, N.D., McEwen, C.N.: Solvent assisted inlet ionization: an ultrasensitive new liquid introduction ionization method for mass spectrometry. Anal. Chem. 83, 3981-3985 (2011)

36. Pagnotti, V.S., Inutan, E.D., Marshall, D.D., McEwen, C.N., Trimpin, S.: Inlet ionization: a new highly sensitive approach for liquid chromatography/mass spectrometry of small and large molecules. Anal. Chem. 83, 7591-7594 (2011)

37. Wang, B., Inutan, E.D., Trimpin, S.: A new approach to high sensitivity liquid chromatography-mass spectrometry of peptides using nanoflow solvent assisted inlet ionization. J. Am. Soc. Mass Spectrom. 23, 442 445 (2012)

38. Tang, K., Allman, S.L., Chen, C.H.: Matrix-assisted laser desorption ionization of oligonucleotides with various matrices. Rapid Commun. Mass Spectrom. 7, 943-948 (1993)

39. Fitzgerald, M.C., Parr, G.R., Smith, L.M.: Basic matrices for the matrixassisted laser desorption ionization mass spectrometry of proteins and oligonucleotides. Anal. Chem. 65, 3204-3211 (1993)

40. Krause, J., Stoeckli, M., Schlunegger, U.P.: Studies on the selection of new matrices for ultraviolet matrix-assisted laser desorption/ionization time-of-flight mass spectrometry. Rapid Commun. Mass Spectrom. 10, 1927-1933 (1996)

41. Pitt, J.J., Gorman, J.J.: Matrix-assisted laser desorption/ionization timeof-flight mass spectrometry of sialylated glycopeptides and proteins using 2,6-dihydroxyacetophenone as a matrix. Rapid Commun. Mass Spectrom. 10, 1786-1788 (1996)

42. Burton, R.D., Watson, C.H., Eyler, J.R., Lang, G.L., Powell, D.H., Avery, M.Y.: Proton affinities of eight matrices used for matrix-assisted laser desorption/ionization. Rapid Commun. Mass Spectrom. 11, 443446 (1997)

43. Stimson, E., Truong, O., Richter, W.J., Waterfield, M.D., Burlingame, A.L.: Enhancement of charge remote fragmentation in protonated peptides by high-energy CID MALDI-TOF-MS using "cold" matrices. Int. J. Mass Spectrom. 169, 231-240 (1997)

44. Xu, N., Huang, Z.H., Watson, J.T., Gage, D.A.: Mercaptobenzothiazoles: a new class of matrices for laser desoption ionization mass spectrometry. J. Am. Soc. Mass Spectrom 8, 116-124 (1997)

45. Eskinja, M., Zollner, P., Schmid, E.R.: Determination of mercapturic acids using 1,4-dihydroxynaphthalene, a new matrix for matrix-assisted UV laser desorption/ionization mass spectrometry. Eur. Mass Spectrom. 4, 157-162 (1998)

46. Green-Church, K.B., Limbach, P.A.: Matrix-assisted laser desorption/ ionization mass spectrometry of hydrophobic peptides. Anal. Chem. 70, 5322-5325 (1998)

47. Horneffer, V., Dreisewerd, K., Lüdemann, H.C., Hillenkamp, F., Läge, M., Strupat, K.: Is the incorporation of analytes into matrix crystals a prerequisite for matrix-assisted laser desorption/ionization mass spectrometry? A study of five positional isomers of dihydroxybenzoic acid. Int. J. Mass Spectrom. 185, 859-870 (1999)

48. Ulmer, L., Mattay, J., Torres-Garcia, H.G., Luftmann, H.: The use of 2[(2E)-3-(4-tert-butylphenyl)-2-methylprop-2-enylidene]malononitrile as a matrix for matrix-assisted laser desorption/ionization mass spectrometry. Eur. J. Mass Spectrom. 6, 49-52 (2000)

49. Chen, Y.T., Ling, Y.C.: Detection of water-soluble vitamins by matrixassisted laser desorption/ionization time-of-flight mass spectrometry using porphyrin matrices. J. Mass Spectrom. 37, 716-730 (2002)

50. Luo, G.H., Marginean, I., Vertes, A.: Internal energy of ions generated by matrix-assisted laser desorption/ionization. Anal. Chem. 74, 6185$6190(2002)$

51. Vertes, A., Luo, G.H., Ye, L., Chen, Y., Marginean, I.: Laser pulse length dependence of internal energy transfer in UV-MALDI-MS. Appl. Phys. A: Mater. Sci. Process. 79, 823-825 (2004)

52. Pashkova, A., Moskovets, E., Karger, B.L.: Coumarin tags for improved analysis of peptides by MALDI-TOF MS and MS/MS. 1. Enhancement in MALDI MS signal intensities. Anal. Chem. 76, 45504557 (2004)

53. Trimpin, S., Räder, H.J., Müllen, K.: Investigations of theoretical principles for MALDI-MS derived from solvent-free sample preparation - Part I. Preorganization. Int. J. Mass Spectrom. 253, 13-21 (2006)
54. Demeure, K., Quinton, L., Gabelica, V., De Pauw, E.: Rational selection of the optimum MALDI matrix for top-down proteomics by in-source decay. Anal. Chem. 79, 8678-8685 (2007)

55. Trimpin, S., Clemmer, D.E., McEwen, C.N.: Charge-remote fragmentation of lithiated fatty acids on a TOF-TOF instrument using matrixionization. J. Am. Soc. Mass Spectrom. 18, 1967-1972 (2007)

56. Batoy, S.M.A.B., Akhmetova, E., Miladinovic, S., Smeal, J., Wilkins, C.L.: Developments in MALDI mass spectrometry: the quest for the perfect matrix. Appl. Spectrosc. Rev. 43, 8485-8550 (2008)

57. Beate, F., Juergen, S.: Recent developments of useful MALDI matrices for the mass spectrometric characterization of apolar compounds. Curr. Org. Chem. 13, 1664-1681 (2009)

58. Solouki, T., Gillig, K.J., Russell, D.H.: Mass measurement accuracy of matrix-assisted laser-desorbed biomolecules - a Fourier-Transform IonCyclotron Resonance mass-spectrometry study. Rapid Commun. Mass Spectrom. 8, 26-31 (1994)

59. Gusev, A.L., Wilkinson, W.R., Proctor, A., Hercules, D.M.: Improvement of signal reproducibility and matrix/co-matrix effects in MALDI analysis. Anal. Chem. 67, 1034-1041 (1994)

60. Shahgholi, M., Garcia, B.A., Chiu, N.H.L., Heaney, P.J., Tang, K.: Sugar additives for MALDI matrices improve signal allowing the smallest nucleotide change (A:T) in a DNA sequence to be resolved. Nucleic Acids Res. 29(e91), 1-10 (2001)

61. Laugesen, S., Roepstorff, P.: Combination of two matrices results in improved performance of MALDI MS for peptide mass mapping and protein analysis. J Am. Soc. Mass Spectrom. 14, 992-1002 (2003)

62. Anderson, J.L., Ding, J., Welton, T., Armstrong, D.W.: Characterizing ionic liquids on the basis of multiple salvation interaction interactions. J. Am. Soc. Mass Spectrom. 124, 14247-14254 (2002)

63. Mank, M., Stahl, B., Boehm, G.: 2,5-Dihydroxybenzoic acid butylamine and other ionic liquid matrixes for enhanced MALDI-MS analysis of biomolecules. Anal. Chem. 76, 2938-2950 (2004)

64. Tholey, A., Heinzle, E.: Ionic (liquid) matrices for matrix-assisted laser desorption/ionization mass spectrometry-applications and perspectives. Anal. Bioanal. Chem. 386, 24-37 (2006)

65. Lietz, C., Inutan, E.D., Wang, B., Trimpin, S.: Laserspray Ionization, Matrix Materials, and Sample Preparation/Ionization Conditions. Proceedings of the 58th ASMS Conference, Salt Lake City, UT, MP27 582, May 23-27 (2010)

66. Wang, B., Lietz, C.B., Inutan, E.D., Leach, S., Trimpin, S.: Laserspray ionization ion mobility spectrometry mass spectrometry: a total solventfree analysis approach at atmospheric pressure. Anal. Chem. 83, 40764084 (2011)

67. Richards, A.L., Marshall, D.D., Inutan, E.D., McEwen, C.N., Trimpin, S.: High-throughput analysis of peptides and proteins by laserspray ionization mass spectrometry. Rapid Commun. Mass Spectrom. 25, $247-250$ (2011)

68. Inutan, E.D., Wang, B., Trimpin, S.: Commercial intermediate pressure MALDI ion mobility spectrometry mass spectrometer capable of producing highly charged laserspray ionization ions. Anal. Chem. 83, 678-684 (2011)

69. Vestal, M.L.: The future of biological mass spectrometry. J. Am. Soc. Mass Spectrom. 22, 953-959 (2011)

70. Chan, T.W.D., Colburn, A.W., Derrick, P.J., Gardiner, D.J., Bowden, M.: Suppression of matrix ions in ultraviolet-laser desorption-scanning electron-microscopy and raman-spectroscopy of the solid samples. Org. Mass Spectrom. 27, 188-194 (1992)

71. Vorm, O., Roepstorff, P., Mann, M.: Improved resolution and very high-sensitivity in MALDI TOF of matrix surfaces made by fast evaporation. Anal. Chem. 66, 3281-3287 (1994)

72. Colby, S.M., King, T.B., Reilly, J.P.: Improving the resolution of matrix-assisted laser desorption/ionization time-of-flight mass-spectrometry by exploiting the correlation between ion position and velocity. Rapid Commun. Mass Spectrom. 8, 865-868 (1994)

73. Cohen, S.L., Chait, B.T.: Influence of matrix solution conditions on the MALDI-MS analysis of peptides and proteins. Anal. Chem. 68, 31-37 (1996)

74. Knochenmuss, R., Dubois, F., Dale, M.J., Zenobi, R.: The matrix suppression effect and ionization mechanisms in matrix-assisted laser desorption/ionization. Rapid Commun. Mass Spectrom. 10, 871-877 (1996)

75. Chen, H.R., Guo, B.C.: Use of binary solvent systems in the MALDITOF analysis of poly(methyl methacrylate). Anal. Chem. 69, 43994404 (1997) 
76. Amado, F.M.L., Domingues, P., Santana-Marques, M.G., FerrerCorreia, A.J., Tomer, K.B.: Discrimination effects and sensitivity variations in matrix assisted laser desorption/ionization. Rapid Commun. Mass Spectrom. 11, 1347-1352 (1997)

77. Worrall, T.A., Cotter, R.J., Woods, A.S.: Purification of contamination peptides and proteins on synthetic membrane surfaces for matrixassisted laser desorption/ionization mass spectrometry. Anal. Chem. 70, 750-756 (1998)

78. Figueroa, I.D., Torres, O., Russell, D.H.: Effects of the water content in the sample preparation for MALDI on the mass spectra. Anal. Chem. 70, 4527-4533 (1998)

79. Krause, E., Wenschuh, H., Jungblut, P.R.: The dominance of arginecontaining peptides in MALDI-derived tryptic mass fingerprints of proteins. Anal. Chem. 71, 4160-4165 (1999)

80. Onnerfiord, P., Ekstrom, S., Bergquist, J., Nilsson, J., Laurell, T., MarkoVarga, G.: Homogeneous sample preparation for automated high throughput analysis with matrix-assisted laser desorption/ionization time-of-flight spectrometry. Rapid Commun. Mass Spectrom. 13, 315-322 (1999)

81. Garden, R.W., Sweedler, J.V.: Heterogeneity within MALDI samples as revealed by mass spectrometric imaging. Anal. Chem. 72, 30-36 (2000)

82. Schuerenbeg, M., Luebbert, C., Eickhoff, H., Kalkum, M., Lehrach, H., Nordhoff, E.: Prestructured MALDI-MS sample supports. Anal. Chem. 72, 3436-3442 (2000)

83. Gobom, J., Schuerenberg, M., Mueller, M., Theiss, D., Lehrach, H., Nordhoff, E.: Alpha-cyano-4-hydroxycinnamic acid affinity sample preparation. A protocol for MALDI-MS peptide analysis in proteomics. Anal. Chem. 73, 434-438 (2001)

84. Trimpin, S., Rouhanipour, A., Az, R., Räder, H.J., Müllen, K.: New aspects in matrix-assisted laser desorption/ionization time-of-flight mass spectrometry: a universal solvent-free sample preparation. Rapid Commun. Mass Spectrom. 15, 1364-1373 (2001)

85. Trimpin, S., Grimsdale, A.C., Räder, H.J., Müllen, K.: Characterization of an insoluble poly(9,9-diphenyl-2,7-fluorene) by solvent-free sample preparation for MALDI-TOF mass spectrometry. Anal. Chem. 74, 3777-3782 (2002)

86. Luxembourg, S.L., McDonnell, L.A., Duursma, M.C., Guo, X.H., Heeren, R.M.A.: Effect of local matrix crystal variations in matrixassisted ionization techniques for mass spectrometry. Anal. Chem. 75, 2333-2341 (2003)

87. Burkitt, W.I., Giannakopulos, A.E., Sideridou, F., Bashir, S., Derrick, P.J.: Discrimination effects in MALDI-MS of mixtures of peptidesanalysis of the proteome. Aust. J. Chem. 56, 369-377 (2003)

88. Zheng, J., Li, N., Ridyard, M., Dai, H., Robbins, S.M., Li, L.: Simple and robust two-layer matrix/sample preparation method for MALDI MS/MS analysis of peptides. J. Proteome Res. 4, 1709-1716 (2005)

89. Sugiura, Y., Shimma, S., Setou, M.: Two-step matrix application technique to improve ionization efficiency for matrix-assisted laser desorption/ionization in imaging mass spectrometry. Anal. Chem. 78, $8227-8235$ (2006)

90. Trimpin, S., Keune, S., Räder, H.J., Müllen, K.: Solvent-free MALDIMS: developmental improvements in the reliability and the potential of MALDI in the analysis of synthetic polymers and giant organic molecules. J. Am. Soc. Mass Spectrom. 17, 661-671 (2006)

91. Hankin, J.A., Barkley, R.M., Murphy, R.C.: Sublimation as a method of matrix application for mass spectrometric imaging. J. Am. Soc. Mass Spectrom. 18, 1646-1652 (2007)

92. Szajli, E., Feher, T., Medzihradszky, K.F.: Investigating the quantitative nature of MALDI-TOF MS. Mol. Cell. Proteom. 7, 2410-2418 (2008)

93. Trimpin, S., Herath, T.N., Inutan, E.D., Wager-Miller, J., Kowalski, P., Claude, E., Walker, J.M., Mackie, K.: Automated solvent-free matrix deposition for tissue imaging by mass spectrometry. Anal. Chem. 82, 359-367 (2010)

94. Trimpin, S., Ren, Y., Wang, B., Lietz, C.B., Richards, A.L., Marshall, D.D., Inutan, E.D.: Extending the laserspray ionization concept to produce highly charged ions at high vacuum on a time-of-flight mass analyzer. Anal. Chem. 83, 5469-5475 (2011)

95. Trimpin, S., Wang, B., Inutan, E.D., Li, J., Lietz, C.B., Pagnotti, V.S., Harron, A.F., Sardelis, D., McEwen, C.N.: A Mechanism for Ionization of Nonvolatile Compounds in Mass Spectrometry: Considerations from MALDI and Inlet Ionization, J. Am. Soc. Mass Spectrom. doi:10.1007/ s13361-012-0414-y

96. McEwen, C.N., Pagnotti, V.S., Inutan, E.D., Trimpin, S.: New paradigm in ionization: multiply charged ion formation from a solid matrix without a laser or voltage. Anal. Chem. 82, 9164-9168 (2010)
97. Schürenberg, M., Schulz, T., Dreisewerd, K., Hillenkamp, F.: Matrixassisted laser desorption/ionization in transmission geometry: instrumental implementation and mechanistic implications. Rapid Commun. Mass Spectrom. 10, 1873-1880 (1996)

98. Galicia, M.C., Vertes, A., Callahan, J.H.: Atmospheric pressure matrixassisted laser desorption/ionization in transmission geometry. Anal. Chem. 74, 1891-1895 (2002)

99. Singh, G., Kapoor, I.P.S., Mannan, S.M., Kaur, J.: Studies on energetic compounds Part 8: thermolysis of salts of $\mathrm{HNO} 3$ and $\mathrm{HClO} 4 . J$. Hazard. Mater. A79, 1-18 (2000)

100. Dyakov, Y.A., Tsai, S.T., Bagchi, A., Tseng, C.M., Lee, Y.T., Ni, C.K.: $355 \mathrm{~nm}$ multiphoton dissociation and ionization of 2,5dihydroxyacetonphenone. J. Phys. Chem. 113, 14987-14994 (2009)

101. Beavis, R.C., Chait, B.T.: Cinnamic acid derivatives as matrices for ultraviolet laser desorption mass spectrometry of proteins. Rapid Commun. Mass Spectrom. 3, 432-435 (1989)

102. Nordhoff, E., Ingendoh, A., Cramer, R., Overberg, A., Stahl, B., Karas, M., Hillenkamp, F., Crain, P.F.: Matrix-assisted laser desorption ionization mass-spectrometry of nucleic-acid with wavelengths in the ultraviolet and infrared. Rapid Commun. Mass Spectrom. 6, 771776 (1992)

103. Mirza, S.P., Raju, N.P., Vairamani, M.: Estimation of the proton affinity values of fifteen matrix-assisted laser desorption/ionization matrices under electrospray ionization conditions using the kinetic method. J. Am. Soc. Mass Spectrom. 15, 431-435 (2004)

104. Dashtiev, M., Wafler, E., Rohling, U., Gorshkov, M., Hillenkamp, F., Zenobi, R.: Positive and negative analyte ion yield in matrix-assisted laser desorption/ionization. Int. J. Mass Spectrom. 268, 122-130 (2007)

105. Nielen, M.W.F., Malucha, S.: Characterization of polydisperse synthetic polymers by size-exclusion chromatography matrix-assisted laser desorption/ionization time-of-flight mass spectrometry. Rapid Commun. Mass Spectrom. 11, 1194-1204 (1997)

106. Bahr, U., Stahl-Zeng, J., Gleitsmann, E., Karas, M.: Delayed extraction time-of-flight MALDI mass spectrometry of proteins above 25,000 Da. J. Mass Spectrom. 32, 1111-1116 (1997)

107. Trimpin, S., Deinzer, M.L.: Solvent-free MALDI-MS for the analysis of biological samples via a mini-ball mill approach. J. Am. Soc. Mass Spectrom. 16, 542-547 (2005)

108. Trimpin, S., Deinzer, M.L.: Solvent-free MALDI-MS for the analysis of a membrane protein via the mini-ball mill approach: a case study of bacteriorhodopsin. Anal. Chem. 79, 71-78 (2007)

109. Trimpin, S., Deinzer, M.L.: Solvent-free MALDI-MS for the analysis of $\beta$-amyloid peptides via the mini-ball mill approach: qualitative and quantitative advances. J. Am. Soc. Mass Spectrom. 18, 1533-1543 (2007)

110. Trimpin, S.: A perspective on MALDI alternatives - total solvent-free analysis and electron transfer dissociation of highly charged ions by laserspray ionization. J. Mass Spectrom. 45, 471-485 (2010)

111. Lavarone, A.T., Williams, E.R.: Mechanism of charging and supercharging molecules in electrospray ionization. J. Am. Chem. Soc. 125, 2319-2327 (2003)

112. Lomeli, S.H., Peng, I.X., Yin, S., Loo, R.R.O., Loo, J.A.: New reagents for increasing ESI multiple charging of proteins and protein complexes. J. Am. Soc. Mass Spectrom. 21, 127-131 (2010)

113. Douglass, K.A., Venter, A.R.: Investigating the role of adducts in protein supercharging with sulfolane. J. Am. Soc. Mass Spectrom. 23, 489-497 (2012)

114. Krüger, R., Karas, M.: Formation and fate of ion pairs during MALDI analysis: anion adduct generation as an indicative tool to determine ionization processes. J. Am. Soc. Mass Spectrom. 13, 1218-1226 (2002)

115. Mirza, U.A., Chait, B.T.: Effects of anions on the positive ion electrospray ionization mass spectra of peptides and proteins. Anal. Chem. 66, 2898-2904 (1994)

116. Tarzi, O.I., Nonami, H., Erra-Balsells, R.: The effect of temperature on the stability of compounds used as UV-MALDI-MS matrix: 2,5dihydroxybenzoic acid, 2,4,6-trihydroxyacetophenone, alpha-cyano-4hydroxycinnamic acid, 3,5-dimethoxy-4-hydroxycinnamic acid, norharmane and harmane. J. Mass Spectrom. 44, 260-277 (2009)

117. Price, D.M., Bashir, S., Derrick, P.R.: Sublimation properties of x, ydihydroxybenzoic acid Isomers as model matrix assisted laser desorption ionisation (MALDI) matrices. Thermochim. Act. 327, 167-171 (1999)

118. Caprioli, R.M., Farmer, T.B., Gile, J.: Molecular imaging of biological samples: localization of peptides and proteins using MALDI-TOF MS. Anal. Chem. 69, 4751-4760 (1997) 
119. Altelaar, A.F.M., Klinkert, I., Jalink, K. de Lange, R.P.J., Adan, R.A.H., Heeren, R.M.A., Piersma, S.R.: Gold-enhanced biomolecular surface imaging of cells and tissue by SIMS and MALDI mass spectrometry. Anal. Chem. 78, 734-742 (2006)

120. Ihmels, E.C., Gmehling, J.: Extension and revision of the group contribution method GCVOL for the prediction of pure compound liquid densities. Ind. Eng. Chem. Res. 42, 408-412 (2003)

121. Lay, P.A., Norris, R.K., Witting, P.K.: Cyclic voltammetric and EPR spectroscopic studies on apical substituent effects in radical anions of 9-substituted and 9,10-disubstituted nitroethanoanthracenes. Aust. J. Chem. 49, 1279-1286 (1996)

122. Trimpin, S.: Alternatives in IMS-MS - Total Solvent-free Analysis and Structures of Highly Charged Laserspray Ions. Proceedings of the 58th ASMS Conference, Salt Lake City, UT, ThOC 9:50 am, May 23-27 (2010)

123. Inutan, E.D, Li, J., Manly, C., Wang, B., Trimpin, S.: Laserspray ionization and solvent assisted inlet ionization developments and ion mobility spectrometry mass spectrometry applications. Proceedings of the 60th ASMS Conference, Vancouver, Canada, WP30:627, May 20-24 (2012) 